\title{
Rooftop Unitary Air Conditioner with Integral Dedicated Outdoor Air System
}

\author{
Final Report to: \\ National Energy Technology Laboratory \\ U.S. Department of Energy
}

July 28, 2006

DOE Cooperative Agreement Number DE-FC26-03NT41949

Report prepared by: TIAX LLC

Acorn Park

Cambridge, MA 02140-2390 USA

1-617-498-5000

Reference D0220

Copyright 2006, TIAX LLC. This report was written with support of the U.S. Department of Energy under Cooperative Agreement No. DE-FC26-03NT41949. The Government reserves for itself and others acting on its behalf a royalty-free, nonexclusive, irrevocable, worldwide license for Governmental purposes to publish, distribute, translate, duplicate, exhibit, and perform this copyrighted paper. 


\section{Disclaimer and Notice}

This report was prepared as an account of work sponsored by an agency of the United States Government. Neither the United States Government nor any agency thereof, nor any of their employees, nor any of their contractors, subcontractors, nor their employees, make any warranty, express or implied, or assumes any legal liability or responsibility for the accuracy, completeness, or usefulness of any information, apparatus, product, or process disclosed, or represents that its use would not infringe privately owned rights.

Reference herein to any specific commercial product, process, or service by trade name, trademark, manufacturer, or otherwise, does not necessarily constitute or imply its endorsement, recommendation, or favoring by the United States Government or any agency, contractor, or subcontractor thereof. The views and opinions of authors expressed herein do not necessarily state or reflect those of the Unites States Government or any agency thereof.

Any use which a third party makes of this report, or any reliance on it, or decisions to be made based on it, is the responsibility of said third party. TIAX accepts no duty or care or liability of any kind whatsoever to any such third party, and no responsibility for damages, if any, suffered by any third party as a result of decisions made, or not made, or action taken, or not taken, based on this report. This report may be produced only in its entirety, and only with the prior written consent of TIAX LLC. 


\section{Table of Contents}

TABLE OF CONTENTS .......................................................................................................................... II

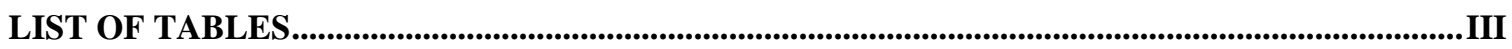

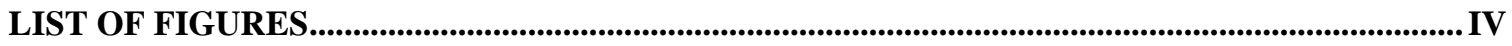

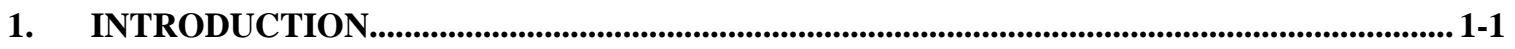

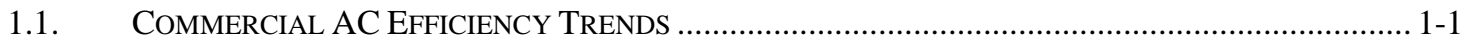

1.2. INCREASING RECOGNITION OF THE IMPORTANCE OF IMPROVED HUMIDITY CONTROL............... 1-2

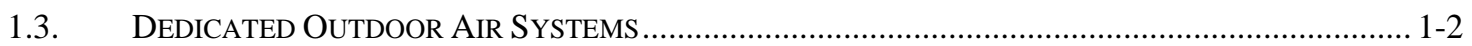

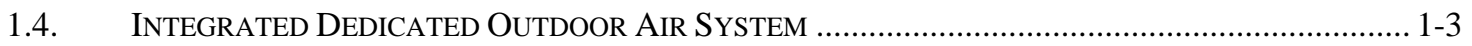

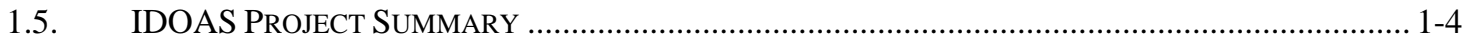

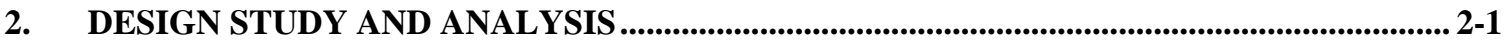

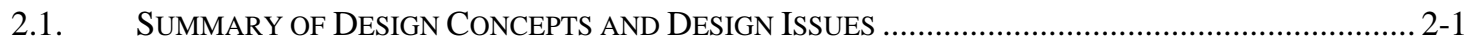

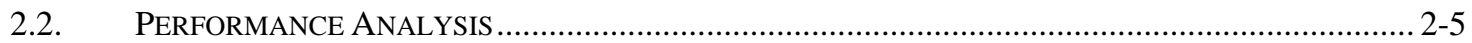

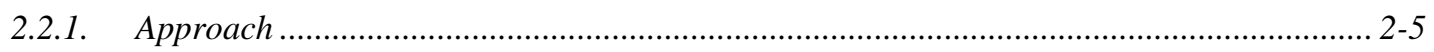

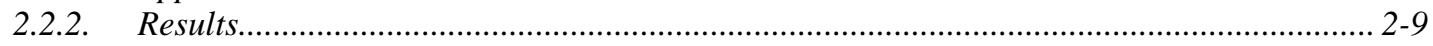

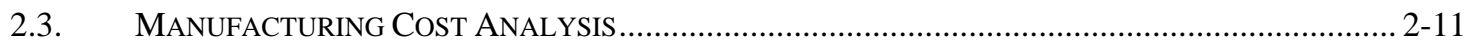

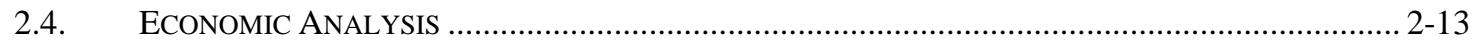

3. PROTOTYPE DESIGN AND FABRICATION................................................................... 3-1

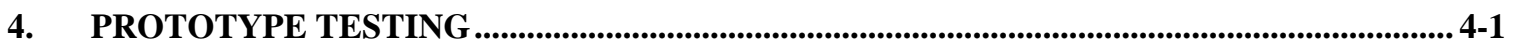

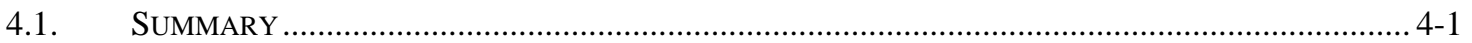

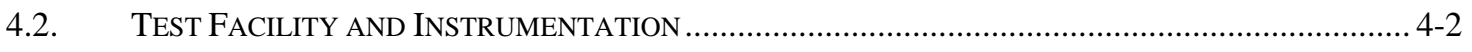

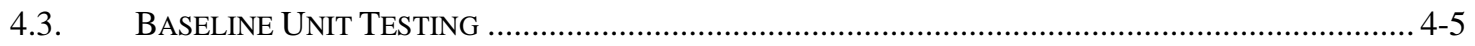

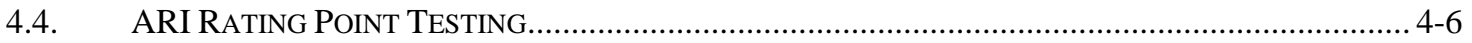

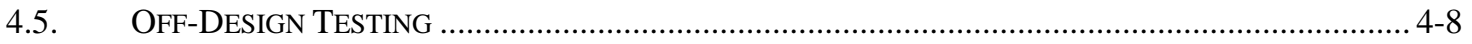

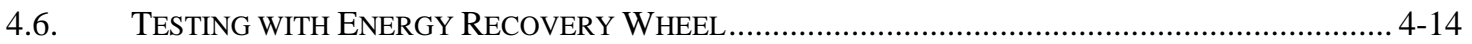

5. CONCLUSIONS AND RECOMMENDATIONS ................................................................ 5-1

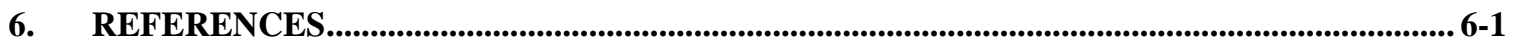

7. APPENDIX 1: CONTROL DESCRIPTION ............................................................................ 7-1

8. APPENDIX 2: DETAILED PROTOTYPE TEST DATA................................................................ 8-1 


\section{List of Tables}

Table 1: Energy Efficiency Standards ...................................................................... 1-1

Table 2: Benefits and Drawbacks of Evaporator Design Approaches............................. 2-3

Table 3: Analyzed Rooftop Unit System Descriptions................................................... 2-8

Table 4: Summary of Energy Use........................................................................... 2-10

Table 5: Manufacturing Cost Estimates............................................................... 2-11

Table 6: VFD Cost Premium ............................................................................ 2-12

Table 7: Cost Impact for One-Blower VAV …………............................................ 2-12

Table 8: Integrated DOAS Economic Summary ………………................................. 2-13

Table 9: Prototype Key Components Compared with the Baseline Unit ......................... 3-1

Table 10: Integrated DOAS Test Facility Measurement Summary ................................. 4-4

Table 11: Baseline Unit Performance Test Data............................................................. 4-5

Table 12: IDOAS Prototype ARI Capacity Test............................................................. 4-7

Table 13: Off-Design Testing Operating Configurations_Full Air Flow ...................... 4-9

Table 14: Off-Design Testing Operating Configurations-Half Air Flow ..................... 4-9

Table 15: Illustration of Off-Design Cycling to Satisfy Desired Space Conditions..... 4-10

Table 16: Comparison of Full-Air-Flow and Half-Air-Flow Performance ................... 4-13

Table 17: Comparison of Standard and ERW Configuration Performance.................... 4-14

Table 18: Examination of Energy Recovery Wheel Capacity Contribution................... 4-15

Table 19: Controlled Components Description ............................................................... 7-1

Table 20: Controls for Laboratory Operation …………….......................................... 7-1

Table 21: Anticipated Field Installation Controls........................................................... 7-2

Table 22: IDOAS Prototype Performance Test Data Summary ……................................ 8-1 


\section{List of Figures}

Figure 1: Dedicated Outdoor Air System General Schematic ...................................... 1-3

Figure 2: Integrated Dedicated Outdoor Air System ............................................... 1-4

Figure 3: Project Organizational Chart ........................................................................ 1-5

Figure 4: Proposed Project Schedule ..................................................................... 1-8

Figure 5: Integrated DOAS Layout Concept ............................................................ 2-1

Figure 6: Increase in Outdoor Air Flow Rate when Return Blower is Shut Off ........... 2-3

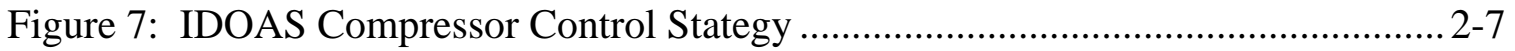

Figure 8: Illustration of Condenser Configurations ..................................................... 2-9

Figure 9: Ranges of Maintaining 50\% Space Humidity ......................................... 2-10

Figure 10: Prototype Evaporator Circuiting and Detail.............................................. 3-2

Figure 11: Prototype Condenser Layout and Circuiting ..............................................3-3

Figure 12: Refrigeration Loop Schematic Diagram................................................ 3-4

Figure 13: Outdoor Air Compressor Valves .......................................................... 3-4

Figure 14: Blower and Motor Assemblies ............................................................... 3-4

Figure 15: Return Blower Discharge Damper ...........................................................

Figure 16: Outdoor Air Throttling Damper ............................................................... 3-6

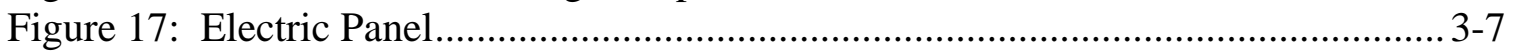

Figure 18: Completed IDOAS Prototype................................................................... 3-7

Figure 19: Energy Recovery Wheel Assembly (Partially Assembled)........................... 3-8

Figure 20: TIAX Air-Conditioner Test Facility....................................................... 4-1

Figure 21: Test Facility for IDOAS Testing without Energy Recovery Wheel ............. 4-3

Figure 22: Test Facility for IDOAS Testing with Energy Recovery Wheel................... 4-3

Figure 23: Off-Design Testing Ambient Conditions ................................................... 4-8

Figure 24: IDOAS Prototype Capacity Data for Full-Flow Off-Design Testing......... 4-10

Figure 25: IDOAS Prototype Comfort Map ......................................................... 4-11

Figure 26: IDOAS Prototype Energy Use Summary—Full Air Flow .......................... 4-12

Figure 27: Latent Capacity Comparison with Condensate Flow .................................. 4-16 


\section{Introduction}

Energy use of rooftop and other unitary air-conditioners in commercial applications accounts for about 1 quad $\left(10^{15} \mathrm{Btu}\right)$ of primary energy use annually in the U.S.

[Reference 7]. The realization that this cooling equipment accounts for the majority of commercial building cooled floorspace and the majority also of commercial building energy use has spurred development of improved-efficiency equipment as well as development of stricter standards addressing efficiency levels.

Another key market driver affecting design of rooftop air-conditioning equipment has been concern regarding comfort and the control of humidity. Trends for increases in outdoor air ventilation rates in certain applications, and the increasing concern about indoor air quality problems associated with humidity levels and moisture in buildings points to a need for improved dehumidification capability in air-conditioning equipment of all types. In many cases addressing this issue exacerbates energy efficiency, and vice versa.

The integrated dedicated outdoor air system configuration developed in this project addresses both energy and comfort/humidity issues.

\subsection{Commercial AC Efficiency Trends}

Efficiency standards for air-conditioning units are summarized in Table 1 below for the most important unit capacity ranges for this type of equipment. The standard for

Table 1: Energy Efficiency Standards

\begin{tabular}{|c|c|c|c|c|}
\hline & \multicolumn{4}{|c|}{ Air-Conditioning Unit Capacity Range (1000 Btu/hr) } \\
\hline Standard & $<65$ & 65 to 135 & 135 to 240 & $>240$ \\
\hline $\begin{array}{l}\text { ASHRAE 90.1-1989 } \\
\text { (current DOE EPAct as of } \\
1 / 1 / 1992 \text { ) }\end{array}$ & SEER 9.5 & EER $8.9^{1}$ & EER $8.5^{1}$ & EER 8.5 \\
\hline ASHRAE 90.1-1999 & SEER 10 & EER $10.3^{1}$ & EER $9.7^{1}$ & EER 9.5 \\
\hline FEMP Recommended & SEER 12.0 & $\begin{array}{l}\text { EER } 11.0 \\
\text { IPLV } 11.4\end{array}$ & $\begin{array}{l}\text { EER } 10.8 \\
\text { IPLV } 11.2\end{array}$ & \\
\hline Energy Star & SEER 13.0 & $\begin{array}{l}\text { EER } 11.0 \\
\text { IPLV } 11.4\end{array}$ & $\begin{array}{l}\text { EER } 10.8 \\
\text { IPLV } 11.2\end{array}$ & \\
\hline $\begin{array}{l}\text { DOE Minimum Efficiency } \\
\text { Standard for Commercial } \\
\text { Units (effective } 1 / 1 / 2010 \text { ), } \\
\text { Reference } 11\end{array}$ & & EER $11.2^{1}$ & EER $11.0^{1}$ & EER $10.0^{1}$ \\
\hline $\begin{array}{l}\text { DOE Minimum Efficiency } \\
\text { Standard for Residential } \\
\text { Units (effective /23/2006) }\end{array}$ & SEER 13.0 & & & \\
\hline CEE Tier 2 & $\begin{array}{l}\text { SEER } 13.0 \\
\text { EER } 11.3^{2}\end{array}$ & $\begin{array}{l}\text { EER } 11.0 \\
\text { IPLV } 11.4\end{array}$ & $\begin{array}{l}\text { EER } 10.8 \\
\text { IPLV } 11.2\end{array}$ & $\begin{array}{l}\text { EER } 10.0 \\
\text { IPLV } 10.4\end{array}$ \\
\hline
\end{tabular}

${ }^{1}$ Air-conditioning units with electric resistance heat or no heat. Units with other types of heating have an EER requirement which is 0.2 lower.

${ }^{2}$ Single-package units. 
residential equipment, having a capacity under $65,000 \mathrm{Btu} / \mathrm{hr}$, is generally expressed in terms of a seasonal energy efficiency ratio (SEER), which represents overall energy use for the cooling season, whereas commercial equipment (defined as having capacity greater than 65,000 Btu/hr) has standards based on design-condition (ARI Standard Conditions) energy efficiency ratio (EER), which represents energy use while operating in a $95^{\circ} \mathrm{F}$ ambient. The EER standard for larger capacity equipment is generally lower than for smaller capacity. However, most of the standards are moving towards adopting a required EER level of about 11 for most of the equipment in the commercial size range (65,000 to 240,000 Btu/hr). Lower efficiencies are allowed for larger equipment.

\subsection{Increasing Recognition of the Importance of Improved Humidity Control}

Dehumidification (latent cooling) has always been part of the function of an airconditioning unit. However, more of the focus has traditionally been on total (sensible plus latent) cooling. Awareness of the need for good humidity control has been increasing, however. Problems with humidity control have emerged in part by increases in outdoor ventilation requirements established by ASHRAE Standard 62-1989, which is still the basis for determination of ventilation rates for most commercial building HVAC systems. The standard requires that outdoor ventilation air be provided continuously. At the same time, some contributors to building cooling loads, such as heat gain through the shell and lighting loads, have been decreasing. In the majority of commercial building floorspace (office buildings, retail spaces, etc.), the outdoor ventilation air includes most of the moisture load. Hence, there has been a trend for increases in the latent portion of the cooling load.

Most unitary air-conditioning units are unable to provide the proper balance of cooling and dehumidification required for the full range of conditions which occur during the cooling season. This is exacerbated by typical operating conditions: the compressors are cycled to provide cooling based on space temperature, although the blower runs continuously to bring in outdoor air. During the compressor off-cycle, moisture which has collected on the coils is re-evaporated. This further reduces the latent capacity of the air-conditioning unit [Reference 8]. During the compressor off-time humidity from outside continues to be drawn into the space without any conditioning. Hence, humidity levels within the space can increase dramatically during the compressor off-cycle. If sensible loads are modest, the compressor(s) will not run for very long, thus leading to out-of-control humidity levels.

Excess space humidity compromises occupant comfort, but can also lead to more serious problems by encouraging the growth of mold [Reference 9] and dust mites [Reference 10], for example.

\subsection{Dedicated Outdoor Air Systems}

One approach to addressing the conditioning and dehumidification issues associated with outdoor ventilation air is use of dedicated outdoor air systems (DOAS) [References 1, 2]. In a system using DOAS, shown in Figure 1 below, the outdoor air is conditioned separately from air which is recirculated from the building space. A separate cooling unit draws in the required outdoor air flow and cools and dehumidifies it. Supply air for these 
units is generally at the space temperature and at a humidity level slightly lower than the space humidity. The remaining space load is served with $100 \%$ recirculating airconditioning units or fan-coil units. This system approach has the following benefits.

- The outdoor-air-only units can more accurately deliver ASHRAE 62 required ventilation air flow.

- There are significant seasonal energy savings from capacity modulation and VAV for the recirculating units.

- The concentrated humidity loads in the outdoor air can be handled directly, more effectively, and more efficiently. By incorporating reheat into the outdoor air unit, this unit can deliver the correct amount of sensible and latent cooling required to condition the outdoor air. In many cases, additional suppression of conditioned outdoor air humidity levels allows the outdoor unit to completely handle the space latent load, thus allowing recirculating-air units to control simply for space dry bulb temperature. Efficient means for provision of dehumidification can be built into the outdoor air unit (runaround coils, heat pipe precool and reheat, hot liquid reheat, total energy recovery, etc.), and the recirculating-air units can condition the space with elevated chilled water temperature or evaporator temperature, since they do not need to provide dehumidification.

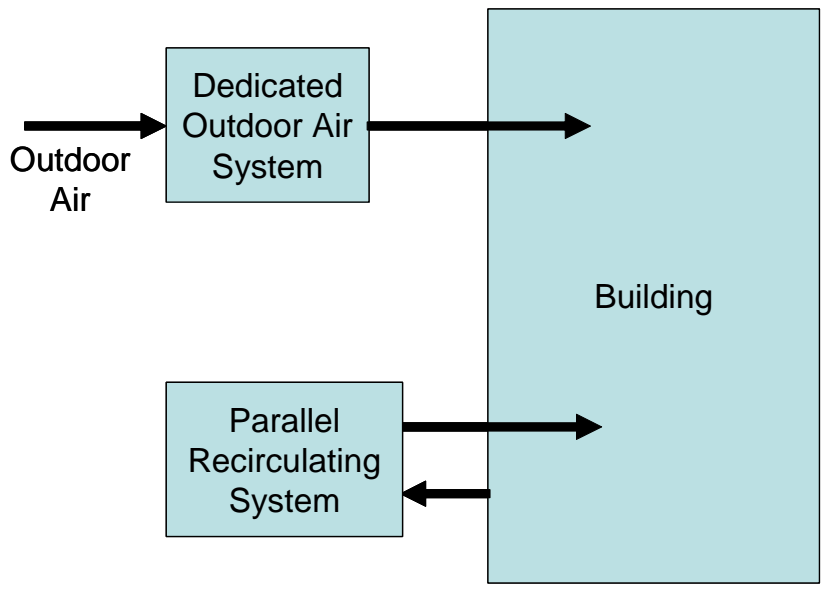

Figure 1: Dedicated Outdoor Air System General Schematic

\subsection{Integrated Dedicated Outdoor Air System}

The integrated dedicated outdoor air system (IDOAS) approach is based on the same approach used by systems using a DOAS unit to separately condition outdoor air. In the IDOAS concept, the separate units serving the outdoor air and the recirculated air are combined into a single package, as shown in Figure 2 below. Separate evaporators serve the two separate air streams: outdoor air to provide required ventilation and return air from the conditioned space. Separate blowers serve these air streams as well. This allows VAV operation of the return air blower and/or allows shutoff of the return air flow when the outdoor air side of the system can provide sufficient conditioning. The air mixes downstream of the blowers and is distributed to the space through common supply ductwork. 


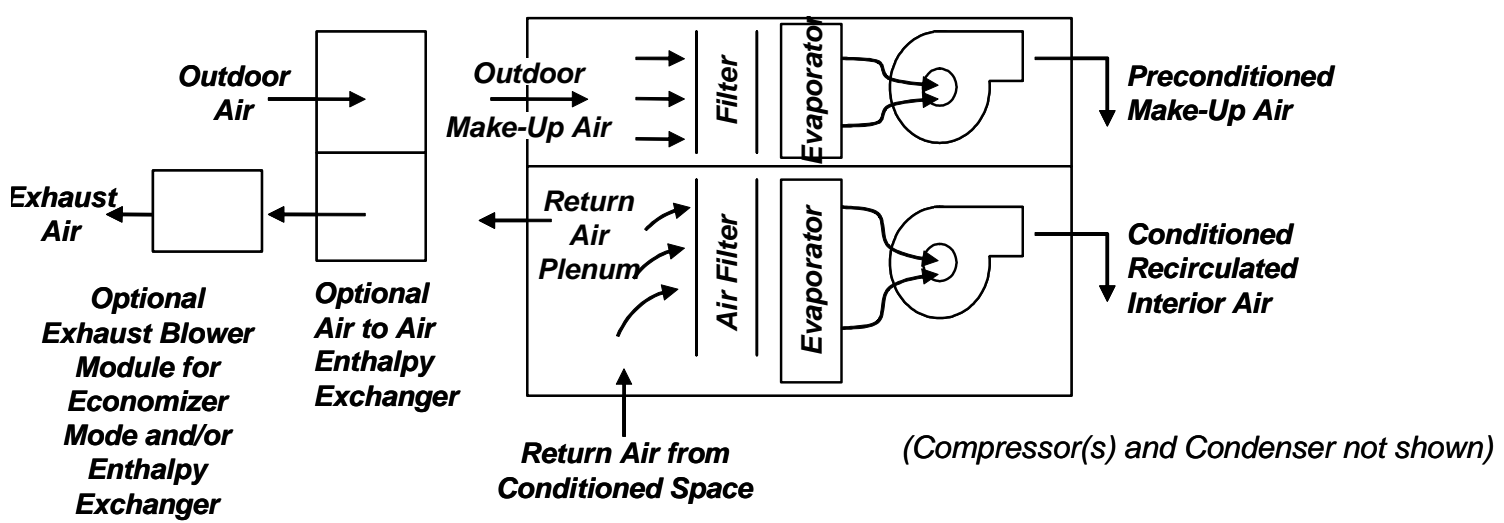

Figure 2: Integrated Dedicated Outdoor Air System

The figure shows an optional total energy recovery exchanger. Integrating enthalpy exchange with the IDOAS unit is facilitated because the unit already has an outdoor air blower, which can be adjusted to compensate for energy recovery exchanger airside pressure drop. An exhaust blower would be required to compensate for air pressure drop on the exhaust air side of the enthalpy exchanger (to avoid building pressurization) and would be incorporated with the enthalpy exchanger package. Alternatively, an exhaust blower could be integrated with the unit to provide relief for economizer mode operation. The advantages of the IDOAS as compared with the use of separate systems for achieving DOAS benefits include the following.

- $\quad$ Reduced cost for incorporating DOAS functionality by combining the two units in a single package.

- Integrated control of the outdoor and return air can be provided with a factorysupplied control system, thus reducing the cost of controls.

\subsection{IDOAS Project Summary}

This project has been carried out under DOE Cooperative Agreement Number DE-FC2603NT41949. The project was selected for funding as a result of competitive solicitation DE-PS26-03NT41635-02 for proposals for R\&D projects addressing energy use in HVAC and other equipment.

The DOE Technical Program Manager for the project is Arun Vohra. Contract Administration is managed by the National Energy Technology Laboratory (NETL). The NETL technical program manager is Paul Giles. The TIAX principal investigator is John Dieckmann. The project is being carried out with Carrier Corporation as the commercialization partner. Richard Lord is the key Carrier Point of Contact. An organizational chart for the project is shown in Figure 3 below. 


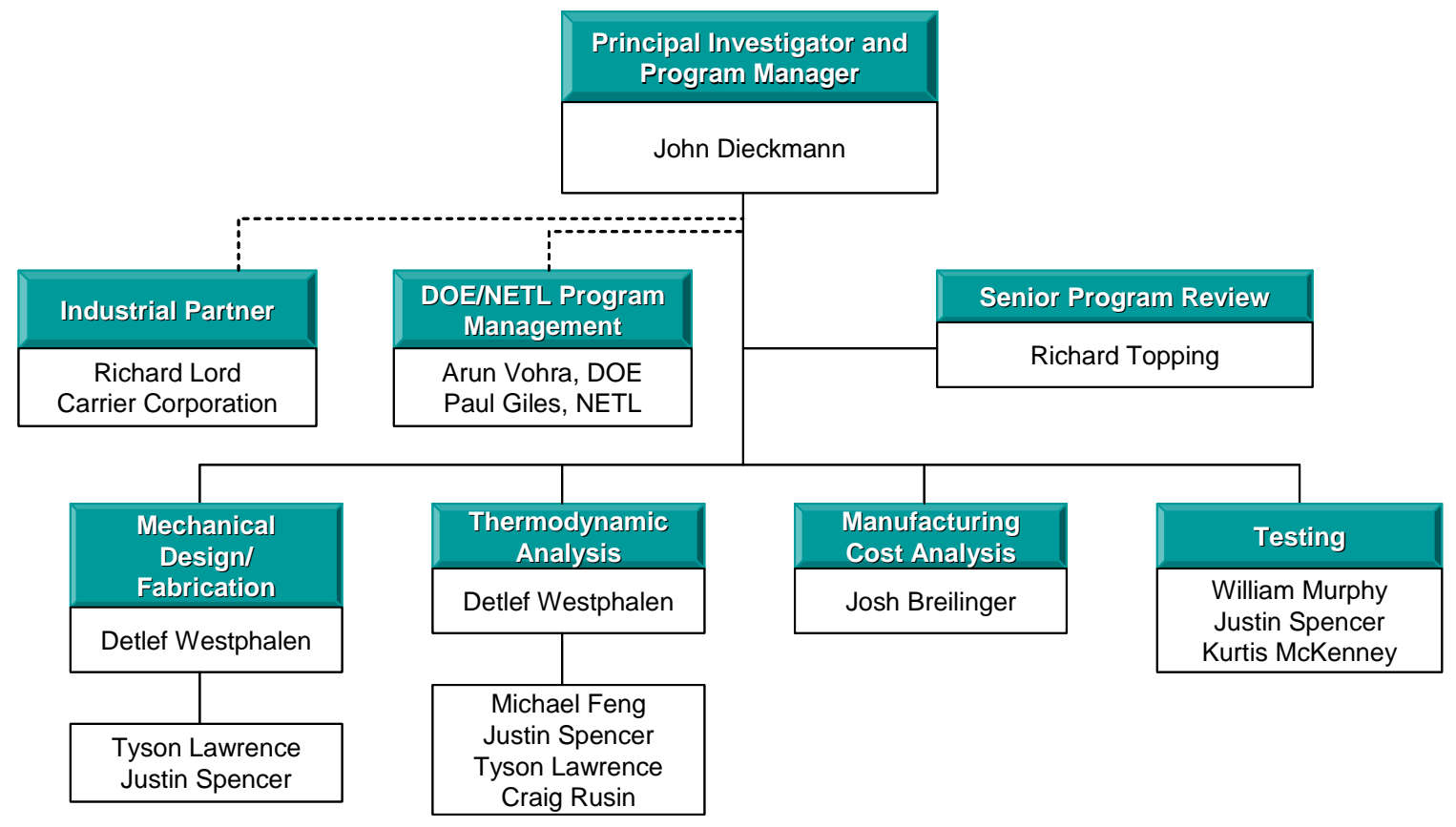

Figure 3: Project Organizational Chart

The objective of the project has been to develop a design of a 10-ton nominal capacity IDOAS unitary rooftop unit, and to build and test a prototype. The work consisted of the following tasks.

- Task 1: Analyze Performance and Manufacturing Cost of Design Options

- Task 2: Detailed Design

- Task 3: Prototype Fabrication

- Task 5: Developmental Testing

- Task 5: Performance Testing

- Task 6: Reporting

A detailed description of the work follows.

\section{Task 1: Analyze Performance and Manufacturing Cost of Design Options}

The various options for development of a high-efficiency commercial rooftop unitary air conditioner with integrated DOAS were analyzed to determine the optimum configuration of the unit for achieving high efficiency, superior comfort levels, and reasonable cost. The work focused on the cooling side of the unit, even though the design features would also improve heating efficiency. The impacts of the proposed performance-enhancing design options were quantified, and a final product configuration was developed. The steps in this process were as follows.

Conventional Unit Benchmarking: Detailed manufacturing cost data for conventional 10 ton rooftop air conditioners at the 9, 10, and 11 EER levels were assembled based on previous work. These baseline cost models were the basis for subsequent estimation of the manufacturing cost impact of integrating a DOAS. 
Key Component Data Gathering: Design information about the key rooftop unit components was obtained from suppliers and our commercialization partner.

Rooftop Unit with DOAS Modeling-Performance: Computer-based models of the baseline and the integrated-DOAS rooftop units were developed. Seasonal performance and energy use was calculated using a three-dimensional matrix of conditions representing building operating status (occupied/unoccupied), ambient temperature, and ambient humidity. Hourly space cooling and heating load data developed in previous projects for representative building models were allocated into the three-dimensional matrices for our analysis. The baseline rooftop unit model was based on published performance data and used a spreadsheet as the calculation platform. The integrated DOAS model was based on correlations of refrigeration system performance analyses. Operating strategy for the integrated DOAS unit was to attempt to satisfy both space temperature and humidity requirements, resulting in a more complicated calculation scheme than for the baseline unit analysis. For this reason, the integrated DOAS unit analysis was created using MatLab and Simulink computing tools. The models allow accurate estimations of the impact of design options on annual energy use.

Rooftop Unit with DOAS Modeling-Cost: The rooftop unit cost was also modeled. A cost estimating spreadsheet was constructed based on similar cost estimation work we have done in support of DOE efficiency standards development for residential central air conditioners, and commercial unitary air conditioners. Manufacturing costs were estimated for the range of rooftop unit design configurations under consideration.

The optimum design configuration was developed through an iterative process of parameter adjustment and energy use and cost estimation. The rooftop unit computer models were used to optimize system configuration of the following variables: key component selections, energy recovery wheel sizing, compressor capacities for each air path, compressor control approach, optimum evaporator capacity and corresponding temperatures for each air path (at design and off-design conditions), condenser air flow, condenser fan and indoor blower fan selection. The outcome of Task 1 was a summary of near-optimum design configurations with their estimated EER, annual energy use, and preliminary cost estimate. A recommendation regarding preferred approach was reviewed with our industrial partner and with DOE at formal review meetings.

\section{Task 2: Detailed Design}

A detailed design for the rooftop unit prototype was prepared. This included selection of key components (compressors, heat exchangers, blowers, fans, etc.) and preparation of CAD models and drawings to support component procurement and fabrication. The design was based on converting a baseline rooftop unit to integrated DOAS design. We designed the prototype unit for flexibility to be used for the range of testing which was planned. It has variable-speed drives for its blowers to allow operation as a VAV unit, but testing work also addressed constant-speed configuration. Furthermore, it was configured to allow easy integration of an energy recovery wheel, and allowed switching of the outdoor air refrigeration circuits so that conditioning of the outdoor air which is pretreated by the wheel could be done using 50\% compressor capacity. 


\section{Task 3: Prototype Fabrication}

A baseline 11 EER rooftop unit was provided by Carrier. After testing of the baseline unit, it was gutted and converted to the integrated DOAS design. An industrial programmable logic controller was used to provide sufficient flexibility to incorporate the range of control options which we wanted to investigate.

\section{Tasks 4 and 5: Developmental and Performance Testing}

The baseline 11EER rooftop unit was first tested to confirm that we are getting accurate results with our test facility.

After fabrication of the integrated DOAS rooftop unit prototype, testing of this unit started. A series of modifications were made to the test facility, to provide separate, independent conditioning and measurement of temperature, humidity, and mass flow rate of both conditioned air paths - the recirculated air stream and the outdoor make-up air stream - as needed to assure accurate testing of the dual-path DOAS configuration. Checkout testing was carried out to assure proper operation of the unit. Subsequently a test sequence was carried out to check operation at ARI design conditions and then to test DOAS unit performance at a series of ambient conditions representing a broad range of cooling season conditions. The test sequence focused primarily on operation with external static pressure consistent with ARI design conditions ( 0.2 in wc). The test sequence included operation for both single-speed and VAV configurations. In addition, the test sequence also addressed operation with an energy recovery wheel.

\section{Task 6: Reporting}

Reporting has been consistent with the DOE Reporting Requirements. Upon program start, the Federal Assistance Milestone Plan (DOE F 4600.3) was submitted. A Project Status Report covering technical progress was submitted monthly. The Financial Status Report (SF-269) was submitted quarterly. The final report was submitted first as a draft and subsequently was finalized after DOE review. The proposed program schedule is shown in Figure 4 below. 


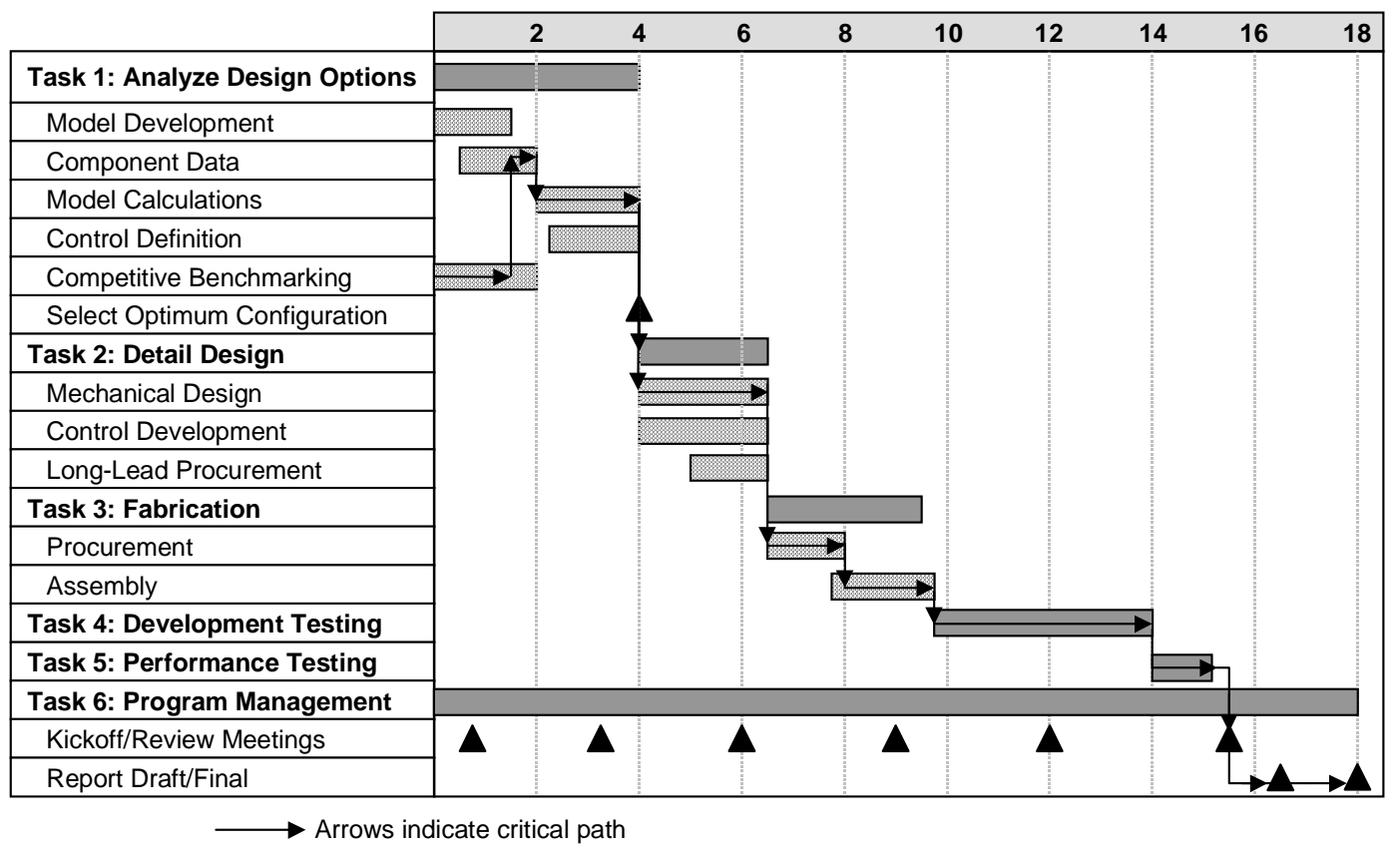

\section{Figure 4: Proposed Project Schedule}

The schedule was extended on several occasions by a total of 7 months. Delay was primarily associated with issues experienced during testing with the operation of the test facility and the challenges in converting the test facility to properly allow measurement for the dual-air-flow arrangement of the prototype rooftop unit. 


\section{Design Study and Analysis}

Design study and analysis which was done to support design decisions is described in this section. The analysis included performance and energy use analysis as well as manufacturing cost analysis. System layout investigation was carried out to assist in selection of components. In addition, a number of issues associated with the system performance and control were investigated.

\subsection{Summary of Design Concepts and Design Issues}

The main IDOAS design goals were to provide improved performance and reduced energy use with little or no cost premium. Design guidelines developed during discussion with our industrial partner, Carrier Corporation, include:

- Use the same basic layout as the Carrier 48HJ012, a 10-ton 11-EER unit. Although the industrial partner did not put significant importance on this aspect of the design, we felt that it was important, in order to show that design changes associated with the IDOAS design could be minimal.

- R-410A refrigerant.

- Develop a design concept which is adaptable to a range of product from a "basic" unit which would have broad market appeal (key driver is cost minimization) to "upgraded" units for customers willing to pay a little more for better performance or lower energy use.

- Use common components. For example, we chose to use Copeland compressors.

- The design targeted a broad range of applications including office space, retail, and light industry which have modest requirements for amounts of outdoor air. The outdoor air flow rate is about $800 \mathrm{scfm}$, but varies depending on building type, building loads, and design ambient conditions.

- The design should allow easy integration of an energy recovery wheel.

The basic IDOAS unit layout concept is illustrated in Figure 5 below.

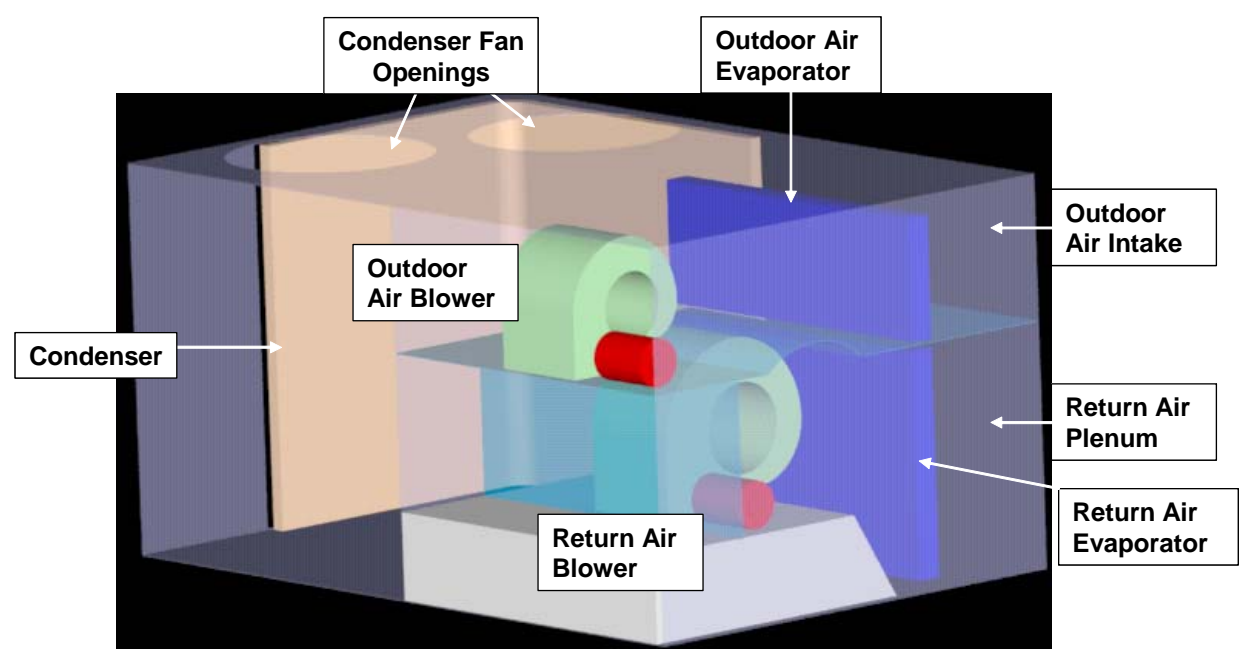

Figure 5: Integrated DOAS Layout Concept 
The condenser-side layout is nearly identical to that of the 48HJ012, except for compressor selection and placement, and piping. The evaporator side is more dramatically modified. This side of the unit is split into an outdoor air (OA) path on top and a return air (RA) path on the bottom. This arrangement allows the unit to retain its configuration allowing duct connections both downward and to the side. Outdoor air is drawn in from the rear of the unit as shown in the figure. A horizontal plenum separates the two air flow paths, from the air inlet to the furnace box, into which both of the blowers discharge. Some modification of the furnace box may be required in order to allow for the changes in air flow, but the details of these changes were not investigated during this project.

Design issues which were addressed during the work include the following.

- Selection of compressors and design of heat exchangers for good performance over the range of applicable operating conditions (ambient conditions).

- Balance of compressor capacity variation with compressor cost. A decision was made to use multiple single-speed compressors due to cost considerations.

- Selection of return air flow rate.

- The design concept described above which uses a single heating section and a single distribution duct leads to some outdoor air flow control issues which would not occur for a unit with separate ducting. In particular, allowing for shutdown of the return blower when space conditioning needs are satisfied (i.e. to reduce energy use) can result in an increase in outdoor air flow rate.

- Incorporation of economizing and easy integration of the energy recovery wheel.

Sizing of compressors and heat exchangers was carried out based on iterations of the performance analysis described in more detail in Section 2.2. A number of design strategies were considered: (1) operating the return air refrigeration circuit at high evaporating temperature to maximize EER, (2) using the return circuit to precool the outdoor air, (3) different evaporator circuit split arrangements including interlacing, front/back, and top/bottom, and (4) a range of return air flow rates. Some of the benefits and drawbacks of these strategies are summarized in Table 2 below.

Evaporator air flow rates from 1,800 to 3,500 scfm were investigated. Surprisingly, the blower power increase associated with higher air flow was high enough that raising the evaporating temperature by increasing air flow was not effective in improving EER. For flow lower than 2,100 scfm, there is significant risk of frosting the evaporator coil. The unit EER was best at 2,100 scfm, although capacity was lower than at 2,800 scfm, thus resulting in higher cost per ton (or per sqft of floorspace served). 
Table 2: Benefits and Drawbacks of Evaporator Design Approaches

\begin{tabular}{|c|c|c|}
\hline & BNㅔㄹㄷS & DRAVVBACKS \\
\hline $\begin{array}{l}\text { Return circuit at high } \\
\text { Evaporating } \\
\text { Temperature }\end{array}$ & •High compressor EER & $\begin{array}{l}\text {-Forces lower outdoor side evap } \\
\text { temp to assure dehumidification. } \\
\text { •Higher return air flow and blower } \\
\text { power. }\end{array}$ \\
\hline $\begin{array}{l}\text { Outdoor Air Precool } \\
\text { with Return Circuit. }\end{array}$ & $\begin{array}{l}\text {-Partial treatment of outdoor air } \\
\text { with high evaporating temp. }\end{array}$ & $\begin{array}{l}\text {-Complex control. } \\
\text {-Leads to smaller, lower-EER } \\
\text { outdoor side compressors }\end{array}$ \\
\hline $\begin{array}{l}\text { Interlaced Return } \\
\text { Evaporator. }\end{array}$ & - Good part load performance. & $\begin{array}{l}\text {-Challenging circuiting, can lead to } \\
\text { larger overall evap width. }\end{array}$ \\
\hline $\begin{array}{l}\text { Front/back Evaporator } \\
\text { Splits. }\end{array}$ & $\begin{array}{l}\text {-Good design point efficiency } \\
\text { due to "staged" air treatment. }\end{array}$ & $\begin{array}{l}\text {-Low downstream evap temps for } \\
\text { moderate conditions. } \\
\text {-Not as good at part load than } \\
\text { interlacing. }\end{array}$ \\
\hline $\begin{array}{l}\text { Top/bottom Split for } \\
\text { Outdoor Evaporator. }\end{array}$ & $\begin{array}{l}\text {-Maintain good } \\
\text { dehumidification performance } \\
\text { at part load. } \\
\text {-Simple circuiting. }\end{array}$ & $\begin{array}{l}\text {-Lower-EER performance for dry } \\
\text { ambient conditions. }\end{array}$ \\
\hline
\end{tabular}

The loss of independent control of outdoor air when the return air flow is varied or stopped for installations using a common supply duct is an issue which was not fully appreciated during conception of the project. Requiring separate supply ducts would solve this problem, but would result in higher system costs by requiring not just separate supply ducts but also separate provision for heating the air. The potential range of increase in outdoor air flow is illustrated in Figure 6 below. These plots are based on the performance curve of a representative blower and the internal pressure/flow characteristics of the outdoor and return air flow paths (evaporators, filters, etc.), with the assumption that supply ductwork pressure drop is proportional to the square of the total flow rate.

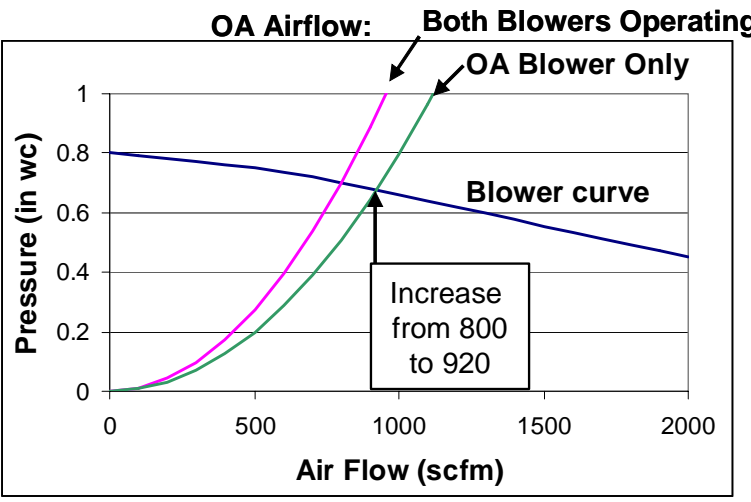

0.2 in wc External Static Application

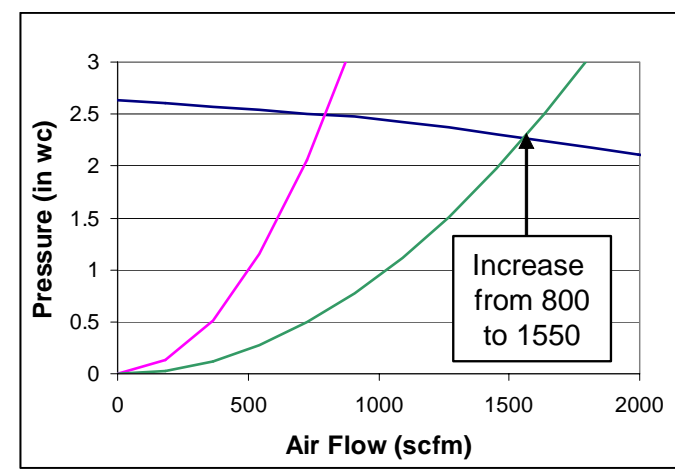

2 in wc External Static Application

Figure 6: Increase in Outdoor Air Flow Rate when Return Blower is Shut Off

The impact of the increased outdoor air flow rate is greatest during winter, since it is during mild periods of the heating season when the most blower energy can be saved by turning off the return blower, and since the heating energy use would be greatly increased 
by the outdoor air flow increase. A number of options could be considered to address this possible increase in outdoor air flow:

- A two-position damper in the outdoor air flow path which throttles when the return blower shuts off.

- It may be possible to alleviate the increase in outdoor air flow by choosing a blower with a very steep pressure/flow curve.

- A VAV outdoor air blower for which speed is reduced when the return blower is turned off.

- A single VAV blower serving both outdoor and return evaporators with a return-side damper to shut down return flow.

- A bypass damper which allows some return air to be drawn into the outdoor air blower inlet when the return blower shuts off. This could be set so that outdoor air flow rate is unchanged.

Many of these approaches also present an additional challenge of potentially leading to distribution of very cold air to the space, for instance, if there is no provision for heating the outdoor air only. Such an arrangement would require more careful consideration of design changes to the furnace section.

Implementation of economizing in the IDOAS design differs slightly from the approach used in a conventional unit. In the IDOAS, some economizing can be achieved by allowing the outdoor air flow passing through the outside air side of the unit to increase, either with damper action or increase in outdoor air blower speed. Full economizing would likely require using the return blower as well. A damper in the bulkhead separating the outdoor air and return air flow paths would have to open. This damper could be placed upstream or downstream of the evaporators, although the downstream location would not allow use of the return compressors to enhance performance. The return duct inlet would also have to be closed off to get full air flow economizing. A single flap damper could be used to both open access to the outdoor air through the unit's external wall enclosing the return plenum and block off the return air inlet duct, thus possibly providing the simplest approach. In any case, implementation of economizing is no more complicated than with conventional air-conditioning units.

Implementation of energy recovery is straightforward with the anticipated IDOAS design configuration. The arrangement of the return plenum and outdoor air intake (see Figure 5 above) provides an air flow orientation suited specifically for integration of an energy recovery wheel, which is usually divided into outdoor and return air flow halves. The use of an outdoor blower within the IDOAS is convenient for energy recovery wheel integration, because the outdoor blower can be sped up to provide the additional pressure rise required to overcome energy recovery wheel flow losses. Hence, the energy recovery module does not require an outdoor air blower. 


\subsection{Performance Analysis}

Performance analysis was done to determine the conditioning characteristics of the design concepts under consideration as well as their energy use.

\subsubsection{Approach}

The target space conditions for the analysis were $75^{\circ} \mathrm{F}$ DB temperature and $50 \%$ relative humidity. The ASHRAE Standard 55 comfort chart shows a comfort zone which extends to higher temperature and/or humidity, but the chosen conditions represent a better norm than the extreme boundary of the comfort chart. The focus for this analysis was on small office building models, which have been considered reasonably representative of a broad range of applications also including retail buildings and light industry. Performance models were established for both conventional units and for the various IDOAS configurations which were considered. The modeling of the IDOAS configurations was set up with decoupled control of temperature and humidity, to the extent possible for the given system performance range.

The performance analysis was based on building load models developed by Lawrence Berkeley National Laboratory (LBNL) for a range of building types and locations using DOE2 analysis. Load models initially developed by LBNL [Reference 4] were more recently updated to reflect changes in building construction details [Reference 5]. Data for small office buildings were used for this analysis, since such buildings are fairly representative of requirements also for small retail and light industrial applications. The focus has been on smaller buildings, since these are the buildings which are more likely to be using single-package rooftop units for conditioning, rather than central chilled water systems. Load data for two cities, New York City and Fort Worth, were used, in order to provide representative indication of performance with a reasonable number of calculations.

The load data, which are total cooling load and heating loads for each hour of the year for the space not including additional conditioning required for outdoor air, were adjusted as described below to include the impact of outdoor air conditioning and to establish split into latent and sensible portions. The latent loads within the space were attributed to people and were determined based on input data for the LBNL analysis. Outdoor air ventilation loads were determined based on the hourly weather data and the required outdoor air flow rates (determined consistent with ASHRAE Standard 62 requirements for design occupant loading). These adjustments allowed development of hourly loads including outdoor air conditioning broken out into sensible and latent portions which must be treated by the cooling coil(s).

The load data was organized into 3-dimensional bins for subsequent analysis. The bin variables were operating mode (day or night), dry bulb temperature, and absolute humidity. Five-degree spans were used for the temperature bins and spans of 0.0005 $\mathrm{lb} / \mathrm{lb}$ dry air were used for the humidity. Average loads for all of the hours in a given bin were used in subsequent analysis. For cooling season analysis, the night operating modes 
generally were not of interest, since the equipment generally would not be operating at this time, hence analysis focused on the daytime bins.

The baseline units which were analyzed include the Carrier 48HJ012, an 11-EER 10-ton rooftop unit, and the 48TF012, a 9-EER 10-ton unit based on the same chassis. Baseline unit performance was obtained from Carrier product literature [Reference 3]. The literature provides information on total capacity, sensible heat ratio, and power input for the compressor as a function of outdoor temperature and evaporator return air temperature and humidity. Power input for the condenser fans and indoor blower were also obtained from the literature. Analysis was done for the ARI standard rating condition external static pressure of 0.2 in wc for a 10-ton unit. The capacity and power data were converted into correlations which could easily be used in a spreadsheet. In cooling mode, these units are controlled with a thermostat to operate one or two of the 5ton compressor stages to satisfy a desired space dry bulb temperature. The indoor blower was assumed to be operating at all times during occupied hours, and both condenser fans operate whenever one or both compressors operate.

The floorspace served by the unit was determined as a first step in the analysis. This was selected so that the unit meets the sensible load requirement for all but one or two extreme-condition hours of the cooling season. Outdoor air flow was set to provide 0.2 scfm/sqft. A spreadsheet analysis was set up which determines run time for the first and second stage compressor for all of the other less extreme conditions. For each mode/ temperature/humidity bin of the analysis, space humidity level is iterated in order to determine what humidity level would be maintained by the unit for the given condition. Blower power was also determined for cool weather operation to assure that the analysis takes into consideration the year-round impact of evaporator air flow and blower configurations. During the day in the heating season, the blower is assumed to operate full time. During the night, the blower cycles with some percentage of on-time as needed to satisfy the heating load.

A sophisticated analysis was set up to determine IDOAS unit performance using the MatLab computing environment. This was done in order to allow calculation of unit operation as it is controlled to maintain both space temperature and humidity setpoints. The cooling circuit performance of the unit was determined using proprietary heat exchanger performance analysis software and compressor performance data, available from compressor vendors. Correlations for the performance were developed as a function of key variables (air flow, ambient temperature, and evaporator air inlet conditions).

Calculations involving the heat exchangers assumed that superheat and subcooling were both $10^{\circ} \mathrm{F}$. However, correction of the compressor capacities from the standard $20^{\circ} \mathrm{F}$ superheat and $15^{\circ} \mathrm{F}$ subcooling to the $10^{\circ} \mathrm{F}$ levels were not done during the initial analysis. This omission was discovered later, and corrections for this difference have been incorporated in the results reported in this section. 
Setting of floorspace served by the IDOAS unit was done in a fashion similar to the approach for the baseline units, such that sensible load was satisfied for all but 1 or 2 extreme condition hours.

In order to determine the operating state of the IDOAS unit for a given mode/temperature/humidity bin, performance is determined for each possible combination of operating compressors. Since there are up to four compressors, there are up to 16 different combinations of operating compressors (combinations of $0,1,2,3$, and 4 compressors operating), as shown in Figure 7 below. Up to three of these configurations are selected in order to match the total sensible load and to attempt to match the latent load. Because the outdoor air compressor circuits have a lower sensible heat ratio, greater use of the outdoor compressors increases latent load. Three operating configurations are chosen that represent three of the four fields of a square in the compressor operation space as indicated illustratively by the three shaded fields in Figure 7. The three fields are selected by inspection by comparing sensible and latent capacities with the load. For configurations in which none of the return compressors are operating, it is assumed that the return blower is shut off to save power. The combination of operating time of each of the three configurations is determined which satisfies the sensible load and attempts to satisfy the latent load. Once operating times are determined, average cooling, dehumidification, and power input is calculated for the particular bin.

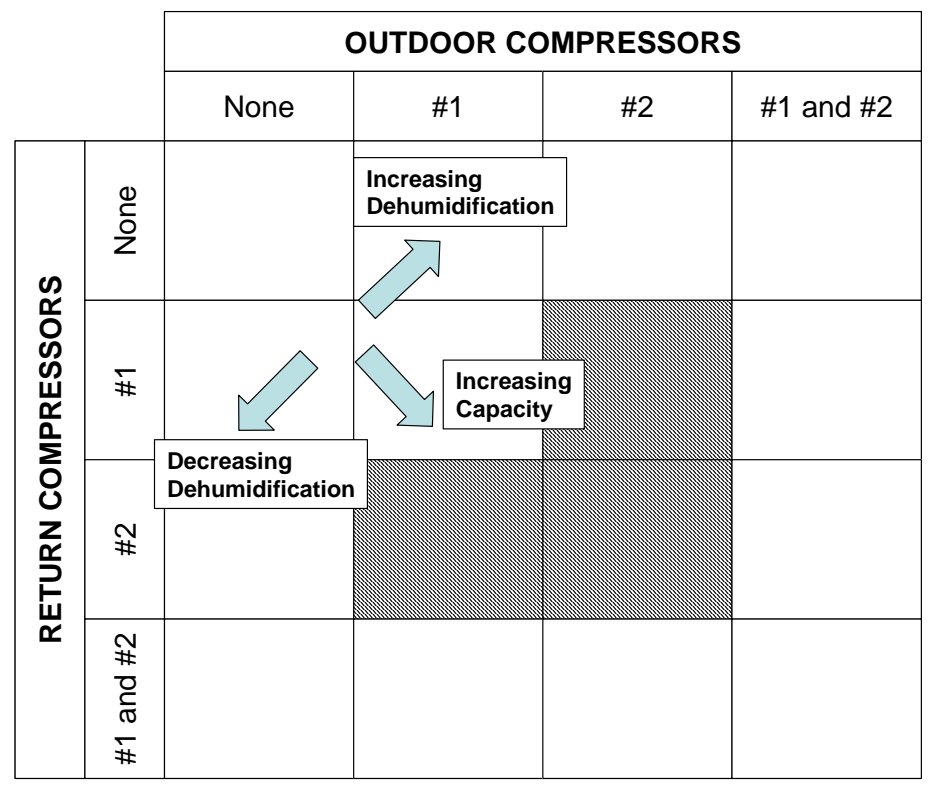

Figure 7: IDOAS Compressor Control Strategy

The analysis determined whether latent loads were matched by average unit capacity but did not iterate to determine adjusted space humidity levels. Adjustment to energy use was made after the initial calculation to address the bins for which there was excessive latent load.

As with the baseline unit(s), blower operation during the heating season was also considered. The return blower was assumed to operate for the heating unit on-time, 
although it may be possible to provide sufficient heating with the lower outdoor air flow. This latter option could provide additional savings which have not be calculated and reported in subsequent sections.

A variety of IDOAS system configurations were analyzed. The key system configurations analyzed are summarized in Table 3 below. The ZP model compressors are Copeland R-410A hermetic scroll compressors. The $\mathrm{H}$ model compressors are Bristol hermetic reciprocating compressors, which were used only when the capacity range of the Copeland scroll series was not low enough. The differences for a given configuration in outdoor air flow for the two cities examined are the result of higher loads in Fort Worth, which make it necessary to reduce the floorspace and hence the outdoor air flow at a constant $0.2 \mathrm{scfm} / \mathrm{sqft}$.

Table 3: Analyzed Rooftop Unit System Descriptions

\begin{tabular}{|c|c|c|c|c|c|c|c|}
\hline \multirow[t]{2}{*}{ System } & \multirow[t]{2}{*}{ Circuit } & \multirow[t]{2}{*}{ Compressors } & \multirow[t]{2}{*}{ Evaporators } & \multicolumn{2}{|c|}{ Air Flow } & \multirow{2}{*}{$\begin{array}{c}\text { Evaporator } \\
\text { Split }\end{array}$} & \multirow{2}{*}{$\begin{array}{c}\text { Condenser } \\
\text { Split }\end{array}$} \\
\hline & & & & NYC & Ft. Worth & & \\
\hline Baseline 11 EER & Main & $\begin{array}{l}\text { Baseline } 11 \text { EER } \\
\text { (2 scroll, } 4.5 \text { tons) }\end{array}$ & $40 \times 404$ rows & 3200 & 3200 & Top/Bottom & Top/Bottom \\
\hline Baseline 9 EER & Main & $\begin{array}{c}\text { Baseline } 9 \text { EER } \\
\text { (2 recips, } 4.5 \text { tons) }\end{array}$ & $36 \times 403$ rows & 4000 & 4000 & Top/Bottom & Top/Bottom \\
\hline \multirow[t]{2}{*}{ DOAS Version 1} & Return & ZP36, ZP26 & OA Precool $40 \times 102$ rows, & 3500 & 3500 & Interlaced & \multirow[t]{2}{*}{ Note 1} \\
\hline & Outdoor & 2 H89B153 & $40 \times 12,3$ rows & 846 & 750 & Top/Bottom & \\
\hline \multirow[t]{2}{*}{ DOAS Version 2B } & Return & ZP36, H89B153 & $26 \times 40,4$ rows & 2800 & 2800 & 3 Front/1 Back & \multirow{10}{*}{ Note 2} \\
\hline & Outdoor & 2 ZP26 & $14 \times 40,4$ rows & 836 & 750 & 2 Front/2 Back & \\
\hline \multirow[t]{2}{*}{ DOAS Version $2 \mathrm{C}$} & Return & ZP54 & $26 \times 40,4$ rows & 2100 & 2100 & None & \\
\hline & Outdoor & 2 ZP26 & $14 \times 40,4$ rows & 798 & 722 & 2 Front/2 Back & \\
\hline \multirow[t]{2}{*}{ DOAS Version 2D } & Return & 2 ZP26 & $26 \times 40,4$ rows & 2800 & 2800 & 2 Front/2 Back & \\
\hline & Outdoor & $2 \mathrm{ZP26}$ & $14 \times 40,4$ rows & 836 & 750 & 2 Front/2 Back & \\
\hline \multirow{2}{*}{$\begin{array}{l}\text { DOAS Version 2E } \\
\text { (2D with less } \\
\text { return air flow) }\end{array}$} & Return & 2 ZP26 & $26 \times 40,4$ rows & 2100 & 2100 & 2 Front/2 Back & \\
\hline & Outdoor & 2 ZP26 & $14 \times 40,4$ rows & 798 & 722 & 2 Front/2 Back & \\
\hline \multirow{2}{*}{$\begin{array}{l}\text { DOAS Version } 2 \mathrm{~F} \\
\text { (2C with more } \\
\text { return air flow) }\end{array}$} & Return & ZP54 & $26 \times 40,4$ rows & 2800 & 2800 & None & \\
\hline & Outdoor & 2 ZP26 & $14 \times 40,4$ rows & 846 & 760 & 2 Front/2 Back & \\
\hline
\end{tabular}

Note 1: Figure 8 Multistack

Note 2: Figure 8 Two by two

The IDOAS Version 1 configuration included an outdoor air precool section served by the return cooling circuits. This generally required downsizing of the outdoor compressors, forcing use of the Bristol H-series reciprocating compressors. The performance of the system with the precool was reasonable for hot humid ambients, but the approach was not very successful for off-design conditions, because (1) in order to maintain the return circuit evaporating temperature higher than the outdoor circuit evaporating temperature, considered necessary to make the precool approach worthwhile, the return air flow had to be relatively high, thus increasing blower power, which makes more of an impact for off-design conditions, (2) the precooling leads to excessive cooling of the outdoor air during off-design conditions, driving down evaporating temperature and operating EER. In addition, incorporation of precooling without adding a separate 
evaporator leads to a side-by-side return/outdoor split of the evaporator section, which is less desirable than the top/bottom configuration which was eventually adopted.

Variations in the DOAS Version 2 series involve different return air flows and different compressor combinations. Otherwise, these configurations are quite similar.

The heat exchanger circuit arrangements which provided the best performance were those in which maximum air flow contacts the active circuit when only one of two compressor circuits is active. This led to a front/back arrangement for the evaporators and a 2 by 2 arrangement for the condenser. Condenser circuits which were analyzed are shown in Figure 8 below.
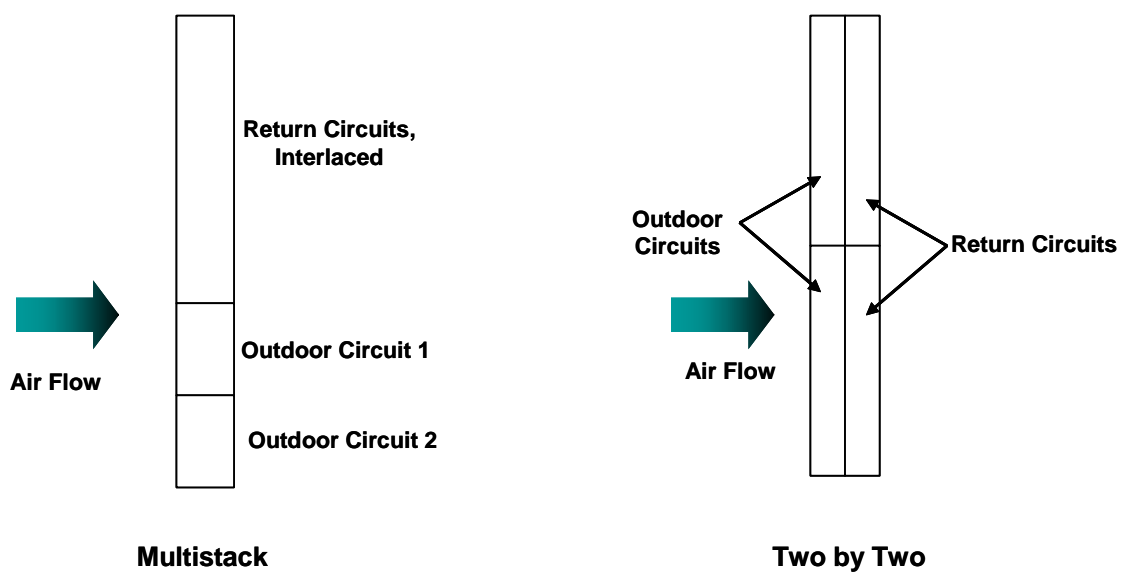

Figure 8: Illustration of Condenser Configurations

\subsubsection{Results}

Annual electric energy use for the key analyzed rooftop unit configurations is summarized in Table 4 below. The IDOAS configurations without VAV are projected to save between $6 \%$ and $18 \%$ as compared with the baseline 11 EER system. The IDOAS configurations with lower air flow are more efficient but have less capacity and thus serve less floorspace. Also, the configurations using the larger ZP54 compressor (rather than two ZP26 compressors) for the return air have more capacity and are slightly more efficient, due to the better performance of the larger compressor.

The conditioning performance of the IDOAS is illustrated for the $2 \mathrm{~F}$ configuration in Figure 9 below. The curves represent the highest level of ambient humidity for which the various units are able to maintain space humidity at $50 \%$ or lower. There is a large region of cooling season ambient conditions for which the IDOAS is able to maintain the target humidity level for which the baseline units cannot. As compared with the 11 EER baseline unit, this represents about 700 occupied hours for New York and 1,050 occupied hours for Fort Worth, about one-third of the total occupied hours. 
Table 4: Summary of Energy Use

\begin{tabular}{|c|c|c|c|c|c|c|c|c|c|c|}
\hline \multirow{3}{*}{ System } & & \multirow{2}{*}{\multicolumn{2}{|c|}{$\begin{array}{c}\text { Energy Use } \\
\left(\mathrm{kWh} / \mathrm{ft}^{\wedge} 2\right)\end{array}$}} & & \\
\hline & \multicolumn{3}{|c|}{ ARI Rating Point } & \multirow{2}{*}{$\begin{array}{c}\text { Blower } \\
\text { Power(W) }\end{array}$} & \multicolumn{2}{|c|}{ Floorspace served } & & & \multicolumn{2}{|c|}{$\begin{array}{l}\text { Energy Use vs. } \\
11 \text { EER baseline }\end{array}$} \\
\hline & Capacity & SHR & EER & & NYC & Ft. Worth & NYC & Ft. Worth & NYC & Ft. Worth \\
\hline Baseline 11 EER & 120.1 & 0.66 & 11.36 & 700 & 4050 & 3655 & 1.94 & 3.30 & 0 & 0 \\
\hline Baseline 9 EER & 114.1 & 0.75 & 8.69 & 1450 & 4200 & 3655 & 2.84 & 4.51 & $+46.3 \%$ & $+36.6 \%$ \\
\hline $\begin{array}{c}\text { Baseline } 11 \text { EER } \\
\text { with Hot Gas } \\
\text { Reheat }\end{array}$ & 120.1 & 0.66 & 11.36 & 700 & 4050 & 3655 & 2.40 & 3.81 & $+23.9 \%$ & $+15.3 \%$ \\
\hline \multirow{2}{*}{ DOAS Version 1} & \multirow{2}{*}{114.7} & \multirow{2}{*}{0.77} & \multirow{2}{*}{10.9} & RA 1000 & \multirow{2}{*}{4228} & \multirow{2}{*}{3753} & \multirow{2}{*}{1.86} & \multirow{2}{*}{3.24} & \multirow{2}{*}{$-4.1 \%$} & \multirow{2}{*}{$-1.8 \%$} \\
\hline & & & & OA 300 & & & & & & \\
\hline \multirow{2}{*}{ DOAS Version 2B } & \multirow{2}{*}{117.2} & \multirow{2}{*}{0.69} & \multirow{2}{*}{11.0} & RA 800 & \multirow{2}{*}{4180} & \multirow{2}{*}{3753} & \multirow{2}{*}{1.72} & \multirow{2}{*}{3.08} & \multirow{2}{*}{$-11.3 \%$} & \multirow{2}{*}{$-6.7 \%$} \\
\hline & & & & OA 200 & & & & & & \\
\hline \multirow{2}{*}{ DOAS Version $2 C$} & \multirow{2}{*}{116.9} & \multirow{2}{*}{0.66} & \multirow{2}{*}{11.5} & RA 400 & \multirow{2}{*}{4038} & \multirow{2}{*}{3610} & \multirow{2}{*}{1.60} & \multirow{2}{*}{2.95} & $-17.5 \%$ & $-106 \%$ \\
\hline & & & & OA 200 & & & & & & \\
\hline DOAS Version 2D & 1178 & 070 & 112 & RA 800 & 4180 & 3753 & 1.73 & 3.06 & $-10.8 \%$ & $-7.3 \%$ \\
\hline with VAV & $11 / .8$ & 0.10 & 11.2 & OA 200 & 4180 & $3 / 53$ & 1.56 & 2.89 & $-19.6 \%$ & $-12.4 \%$ \\
\hline DOA Yercion 2F & 1144 & 069 & 113 & RA 400 & 3990 & 3610 & 160 & 295 & $-17.5 \%$ & $-10.6 \%$ \\
\hline DUAS VerSION $2 \mathrm{E}$ & 114.4 & 0.69 & 11.3 & OA 200 & 3990 & 3610 & 1.60 & & & $-10.6 \%$ \\
\hline DOAS Version 2F & 1194 & 071 & 113 & RA 800 & 4228 & 3800 & 168 & 299 & $13,1 \%$ & $-9.4 \%$ \\
\hline DOAO VETSIOTII & 110.4 & 0.11 & 1.0 & OA 200 & $4<<0$ & 3000 & 1.00 & 2.05 & -10.470 & $-5.4 \%$ \\
\hline
\end{tabular}

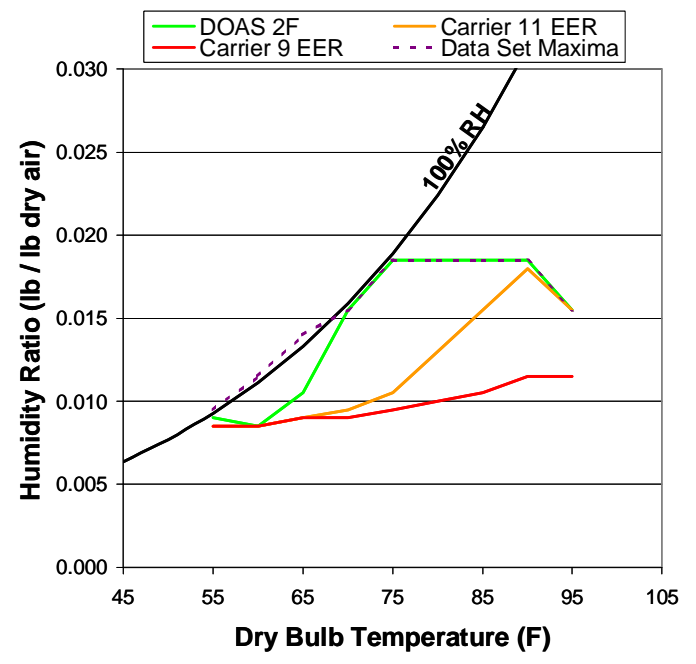

New York

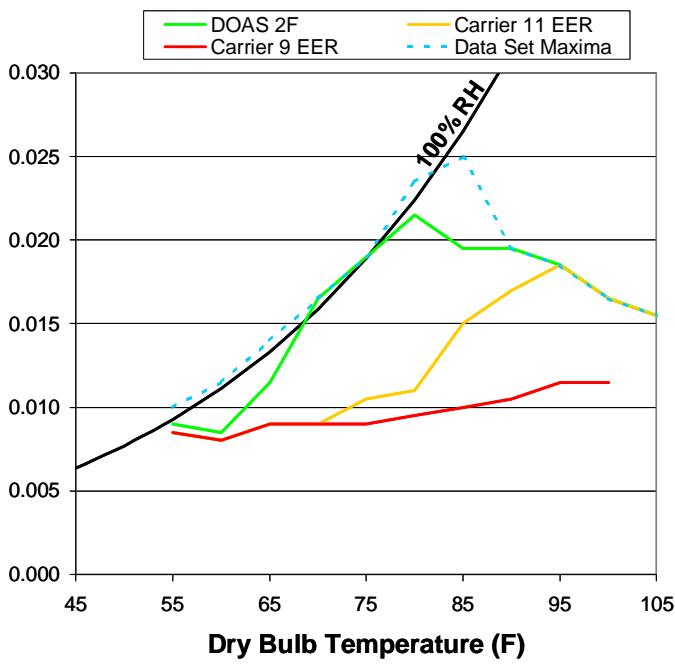

Fort Worth

Figure 9: Ranges of Maintaining 50\% Space Humidity 


\subsection{Manufacturing Cost Analysis}

Manufacturing cost analysis was carried out using cost modeling tools developed during support of DOE rulemaking activities for residential and commercial air-conditioning units. In the cost modeling efforts for these activities, much proprietary cost data was received from air-conditioning unit manufacturers and consolidated to develop average cost estimates for units of varying efficiency level. In order to protect this proprietary information, this report does not report many of the costs at the component level. The manufacturing cost estimates for the baseline and IDOAS units are summarized in Table 5 below.

Table 5: Manufacturing Cost Estimates

\begin{tabular}{|l|c|c|c|c|}
\hline Unit & $\begin{array}{c}\text { Carrier } \\
\text { 48TM-012 }\end{array}$ & $\begin{array}{c}\text { Carrier } \\
\text { 48HJ-012 }\end{array}$ & $\begin{array}{c}\text { IDOAS } \\
\text { Single-Speed }\end{array}$ & $\begin{array}{c}\text { IDOAS } \\
\text { VAV }\end{array}$ \\
\hline Description & 10-ton, 9 EER & 10-ton, 11 EER & & $\begin{array}{c}\text { VAV for both } \\
\text { blowers }\end{array}$ \\
\hline $\begin{array}{l}\text { Manufacturing } \\
\text { Cost Estimate }\end{array}$ & $\$ 2,040$ & $\$ 2,125$ & $\$ 2,423$ & $\$ 2,702$ \\
\hline
\end{tabular}

Note: Economizers not included in total costs.

Cost estimates were based on the following assumptions.

- OEM part prices for the compressor(s) are estimated at an annual volume of 500,000 compressors.

- Prices for other components are estimated based on an annual volume of 72,000 units in the 10-ton product family.

- Purchased parts for the DOAS unitary air-conditioner were estimated by extrapolating along known cost curves.

The cost premium of the two-blower VFD system as compared with the single-speed belt-drive system is $\$ 279$, as summarized in Table 6 below. It is assumed that using a variable-speed drive arrangement allows use of direct-drive blowers, since the speed adjustment of the drive allows in-field setting of speed without the need for belts and pulleys. An additional compressor is needed for the variable-speed arrangements, since modulation of return air flow with no staging or modulation of compressors does not provide an efficiency advantage. The single large return compressor of IDOAS Versions $2 \mathrm{C}$ or $2 \mathrm{~F}$ is replaced with two smaller return compressors, as in Versions 2D or 2E (see Table 3 above). The outdoor air damper, intended for throttling of outdoor air when the return blower turns off, is not required, since the outdoor blower speed can be reduced to avoid the outdoor air flow increase illustrated in Figure 6 above. 
Table 6: VFD Cost Premium

\begin{tabular}{|l|c|}
\hline Item & Cost Impact \\
\hline Variable-Frequency Drive & $\begin{array}{c}\text { Return Blower }+\$ 188 \\
\text { Outdoor Blower }+\$ 75\end{array}$ \\
\hline Shafts, Bearings, Pulleys, Belts & $-\$ 68$ \\
\hline Eliminate Outdoor Air Damper & $-\$ 14$ \\
\hline Added Compressor, Piping, Wiring & $+\$ 98$ \\
\hline TOTAL IMPACT & $+\$ 279$ \\
\hline
\end{tabular}

An alternative IDOAS configuration which incorporates VAV functionality with lower cost would use a single VAV blower with a modulating damper to control air flow split between the return and outdoor air streams. The cost impact (as compared with IDOAS with VAV using two blowers) is summarized in Table 7 below.

Table 7: Cost Impact for One-Blower VAV

\begin{tabular}{|c|c|}
\hline Item & Cost Impact \\
\hline Eliminate Blower & $-\$ 20$ \\
Motor & $-\$ 25$ \\
VFD & $-\$ 35$ \\
\hline Add Damper Set & $+\$ 25$ \\
\hline TOTAL IMPACT & $-\$ 55$ \\
\hline
\end{tabular}




\subsection{Economic Analysis}

Economic analysis combines the energy use analysis of Section 2.2 and the cost analysis of Section 2.3. The payback period analysis for the IDOAS is summarized in Table 8 below. The simple payback period is about 5 years for the small office application for the single-speed IDOAS configuration and increases to about 10 years for VAV

configurations. These estimates are based on an average electricity cost of $\$ 0.08 / \mathrm{kWh}$.

Table 8: Integrated DOAS Economic Summary

\begin{tabular}{|c|c|c|c|c|}
\hline & Baseline & $\begin{array}{l}\text { IDOAS } \\
\text { Version 2F } \\
\text { Single- } \\
\text { Speed }\end{array}$ & $\begin{array}{c}\text { IDOAS } \\
\text { Version 2D } \\
\text { VAV }\end{array}$ & $\begin{array}{c}\text { IDOAS } \\
\text { Version 2D } \\
\text { One-Blower } \\
\text { VAV }\end{array}$ \\
\hline Total OEM Cost & $\$ 2,125$ & $\$ 2,423$ & $\$ 2,702$ & $\$ 2,647$ \\
\hline $\begin{array}{l}\text { Floorspace Served (sqft) } \\
\text { New York } \\
\text { Fort Worth }\end{array}$ & $\begin{array}{l}4,050 \\
3,655\end{array}$ & $\begin{array}{l}4,228 \\
3,800\end{array}$ & $\begin{array}{l}4,180 \\
3,753\end{array}$ & $\begin{array}{l}4,180 \\
3,753\end{array}$ \\
\hline 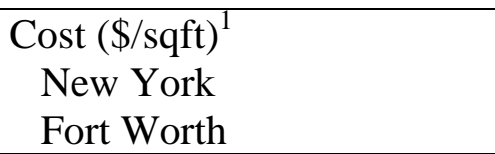 & $\begin{array}{l}\$ 1.31 \\
\$ 1.45\end{array}$ & $\begin{array}{l}\$ 1.43 \\
\$ 1.59\end{array}$ & $\begin{array}{l}\$ 1.62 \\
\$ 1.80\end{array}$ & $\begin{array}{l}\$ 1.58 \\
\$ 1.76\end{array}$ \\
\hline $\begin{array}{l}\text { Net Cost Increase (\%) } \\
\text { New York } \\
\text { Fort Worth } \\
\end{array}$ & N/A & $\begin{array}{c}9 \% \\
10 \%\end{array}$ & $\begin{array}{l}24 \% \\
24 \% \\
\end{array}$ & $\begin{array}{l}21 \% \\
22 \%\end{array}$ \\
\hline $\begin{array}{l}\text { Annual Savings (kWh/sqft) } \\
\text { New York } \\
\text { Fort Worth }\end{array}$ & N/A & $\begin{array}{l}0.26 \\
0.31\end{array}$ & $\begin{array}{l}0.38 \\
0.41\end{array}$ & $\begin{array}{l}0.38 \\
0.41\end{array}$ \\
\hline $\begin{array}{l}\text { Simple Payback Period }(\mathrm{yr})^{2} \\
\text { New York } \\
\text { Fort Worth }\end{array}$ & N/A & $\begin{array}{l}5.3 \\
5.6\end{array}$ & $\begin{array}{l}10 \\
11\end{array}$ & $\begin{array}{c}9 \\
10\end{array}$ \\
\hline
\end{tabular}

Notes: 1. End-User Cost assuming markup of 2.5

2. Based on $\$ 0.08 / \mathrm{kWh}$ 


\section{Prototype Design and Fabrication}

As discussed in Section 2.1, the IDOAS design was based on modification of a Carrier 48HJ012, a 10-ton 11-EER conventional rooftop unit. Carrier provided a rooftop unit of this model which had been used in field testing. The IDOAS unit was built on the chassis of the conventional unit, so many of the structural components are identical. The layout of the key components of the unit is illustrated in Figure 5 of Section 2.1. General definition of the key components of the unit was developed through the analysis described in Sections 2.2 and 2.3. Additional design work carried out as the project transitioned to prototype fabrication served to define the details of construction: sheet metal gauges, refrigerant piping routes, fastener selection, etc. An additional key element of the prototype design phase was specification of electric controls and programming of the selected programmable logic controller (PLC), which was used to provide flexibility in control to allow for a range of different control strategies.

The key components of the prototype are compared with similar components of the baseline unit in Table 9 below. The IDOAS prototype has finer compressor capacity modulation. It was decided to use the four-compressor configuration of the VAVoriented IDOAS designs, so that we could test both single-speed and VAV operation. Total installed compressor capacity is nominally identical, although in this size range the capacity and EER of the larger compressors is slightly better. The heat exchangers are very similar, except for the IDOAS unit having more circuits and having the evaporators physically separated.

Table 9: Prototype Key Components Compared with the Baseline Unit

\begin{tabular}{|c|c|c|c|}
\hline & & IDOAS Prototype & 48HJ012 \\
\hline \multirow[t]{2}{*}{ Compressors } & Return Circuit & (2) 2-ton Copeland ZP26 & \multirow{2}{*}{ (2) 4.5-ton Compressors } \\
\hline & Outdoor Circuit & (2) 2-ton Copeland ZP26 & \\
\hline \multirow[t]{2}{*}{$\begin{array}{l}\text { Evaporator } \\
\text { Face Dimensions--Area } \\
\text { Depth } \\
\text { Design Air Flow (scfm) }\end{array}$} & $\begin{array}{l}\text { Return/ } \\
\text { Main Circuit }\end{array}$ & $\begin{array}{c}40 " \text { x 26"-- } 7.2 \mathrm{sqft} \\
4 \text { Rows (3") } \\
2,800 \mathrm{scfm}\end{array}$ & \multirow{2}{*}{$\begin{array}{l}40 " \text { x 40"-- } 11.1 \text { sqft } \\
4 \text { Rows (3") } \\
3,200 \text { scfm }\end{array}$} \\
\hline & Outdoor Circuit & $\begin{array}{c}40 " \times 14 "--3.9 \text { sqft } \\
4 \text { rows ( } 3 ") \\
800 \text { scfm }\end{array}$ & \\
\hline \multirow[t]{2}{*}{ Blowers and Motors } & $\begin{array}{l}\text { Return/ } \\
\text { Main Air }\end{array}$ & $\begin{array}{c}\text { Delhi G12-9 } \\
\text { 3-phase 208V } 3 \text { hp Motor }\end{array}$ & \multirow{2}{*}{$\begin{array}{l}\text { Lau A15-11A } \\
\text { 3-phase 208V } 3 \mathrm{hp} \text { Motor }\end{array}$} \\
\hline & Outdoor Air & $\begin{array}{c}\text { Delhi GT10-9 } \\
\text { 3-phase 208V 1.5 hp Motor }\end{array}$ & \\
\hline \multicolumn{2}{|l|}{$\begin{array}{l}\text { Condenser: } \\
\text { Face Dimensions--Area } \\
\text { Depth } \\
\text { Air Flow (scfm) }\end{array}$} & \multicolumn{2}{|c|}{$\begin{array}{c}25 \text { sqft } \\
2 \text { Rows (1.8") } \\
7,000 \text { scfm }\end{array}$} \\
\hline \multicolumn{2}{|l|}{ Condenser Fans } & \multicolumn{2}{|c|}{$\begin{array}{l}\text { (2) } 22 \text { inch DIA, } \\
\text { Two } 1 / 4 \text { hp motors }\end{array}$} \\
\hline
\end{tabular}


Circuiting and design detail for the prototype evaporators is shown in Figure 10 below. The circuits were arranged in a front/back configuration in both evaporators. This arrangement maximizes the design-condition performance, particularly for the outdoor air evaporator. This is because the first compressor can operate with a relatively high evaporator temperature, to maximize capacity and EER, while the downstream evaporator compressor can operate with a lower evaporating temperature to maximize dehumidification potential. For both evaporators, the front/back arrangement maximizes contact with outdoor air when just one circuit is operating, without incorporating the complexity associated with full interlacing.
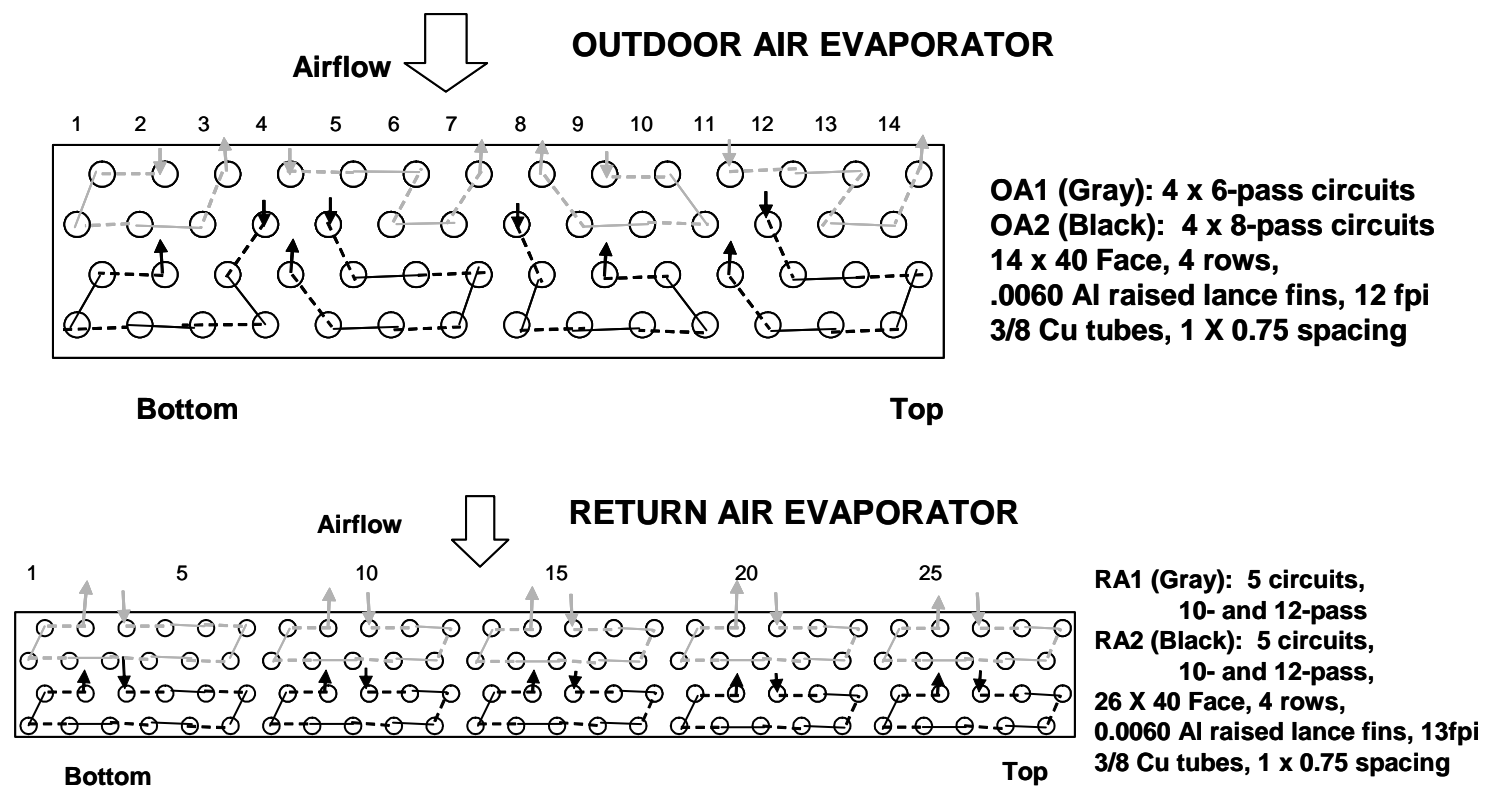

Figure 10: Prototype Evaporator Circuiting and Detail

The upstream group of circuits of the outdoor evaporator was designed to have less tube passes than the downstream group, to avoid pushing evaporating temperature above the range acceptable for the compressors (maximum $55^{\circ} \mathrm{F}$ ). For the return air evaporator, the lowest circuit for each compressor was designed with additional tube passes to account for the reduce evaporator air flow expected in this region. This part of the evaporator is close to the furnace box, which could potentially block air flow.

Evaporators were ordered and received from both Heatcraft and SuperRadiator, to assure that a possibly long lead time for the Heatcraft evaporators would not compromise project schedule. The Heatcraft evaporators were used in the prototype for all of the test work.

Condenser layout and circuiting detail is shown in Figure 11 below. Note that compressor loop designation is defined by the evaporator circuits which it serves. For instance, OA1 is the loop serving the upstream portion of the outdoor air evaporator. The compressor loop arrangement used during the modeling work was modified slightly, 
since more detailed design analysis showed that performance at the design condition could be enhanced if the compressors serving the downstream parts of the evaporators had the upstream portion of the condensers. This arrangement allows for the compressors with the lower evaporating temperatures to operate with the lower condensing temperatures. Each compressor loop is first served with a three-circuit two-pass desuperheating section, followed by 16 passes with single-circuit arrangement. Analysis showed that this was the best configuration for design conditions.

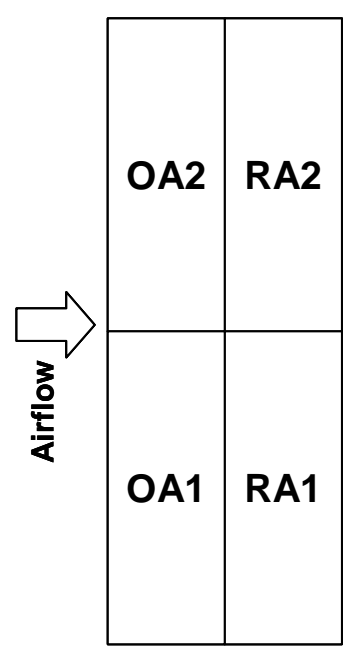

Model

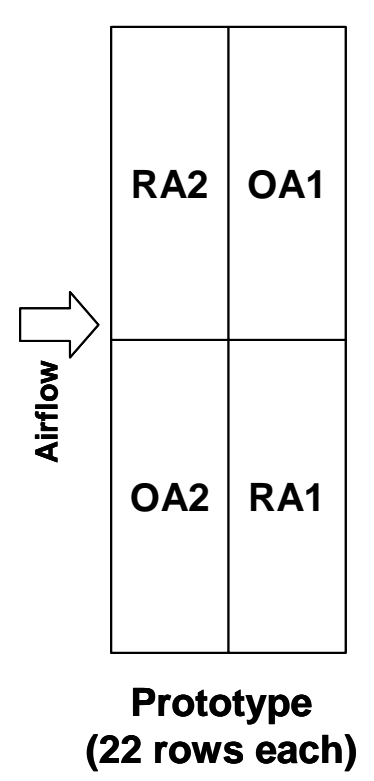

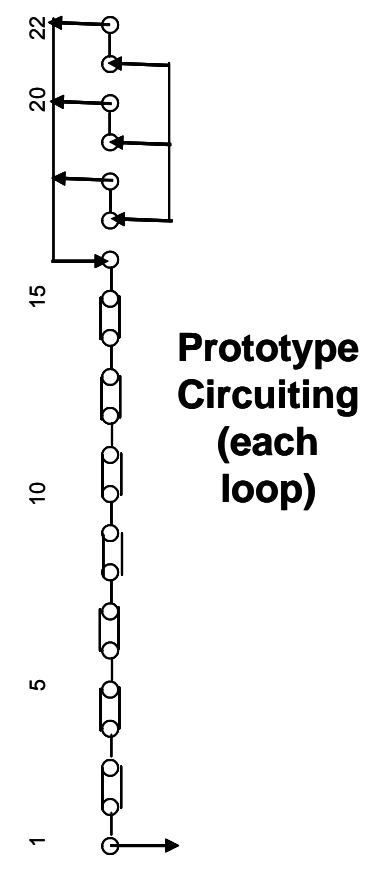

Figure 11: Prototype Condenser Layout and Circuiting

During fabrication, a partially-fabricated condenser for a 48HJ012 unit without return bends attached was provided to us by Carrier. This allowed us to install return bends and headers as needed to implement our circuiting design.

Compressor loop architecture for the prototype was relatively straightforward. Each compressor serves an individual loop separated from the other compressors, the arrangement typical for unitary air-conditioning systems. The piping also included liquid line filter/driers, thermostatic expansion valves and Schraeder valve connections for the suction and discharge of the compressors (see Figure 12). However, arrangement was made for both outdoor air evaporator loops to be served by one of the compressors (OA2), to allow evaluation of whether the energy recovery wheel allows elimination of a compressor, using manual ball valves. This is shown in Figure 13 below. During normal operating, valves SV1 and DV1 are closed and valves SV2 and DV2 are open. For OA2 compressor-only operation, the valve positions are reversed. 


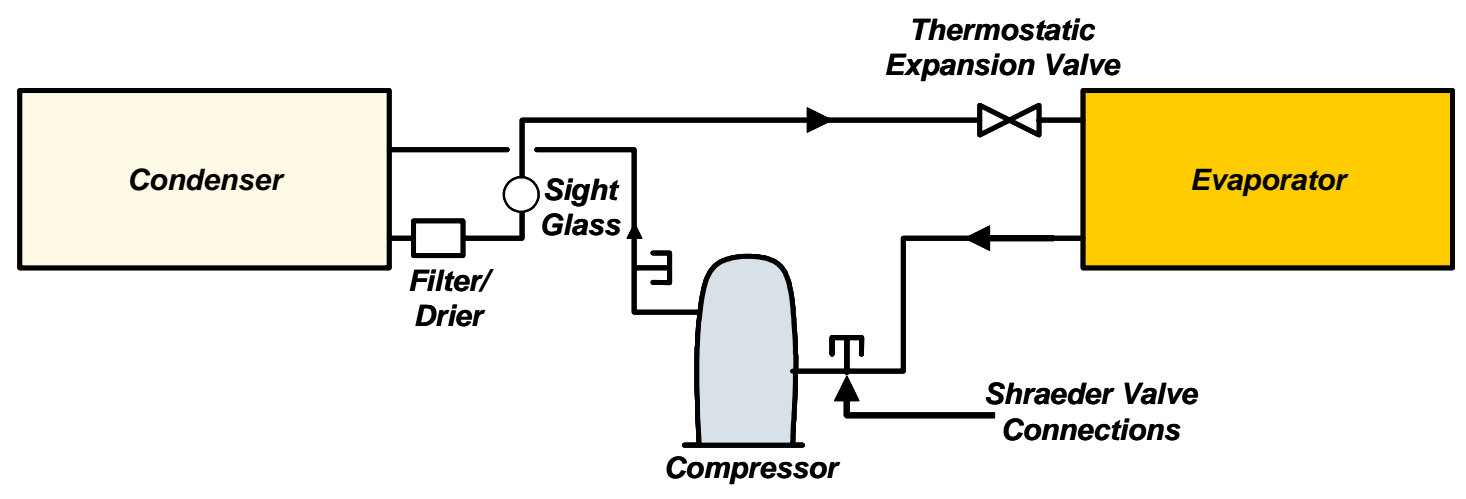

Figure 12: Refrigeration Loop Schematic Diagram

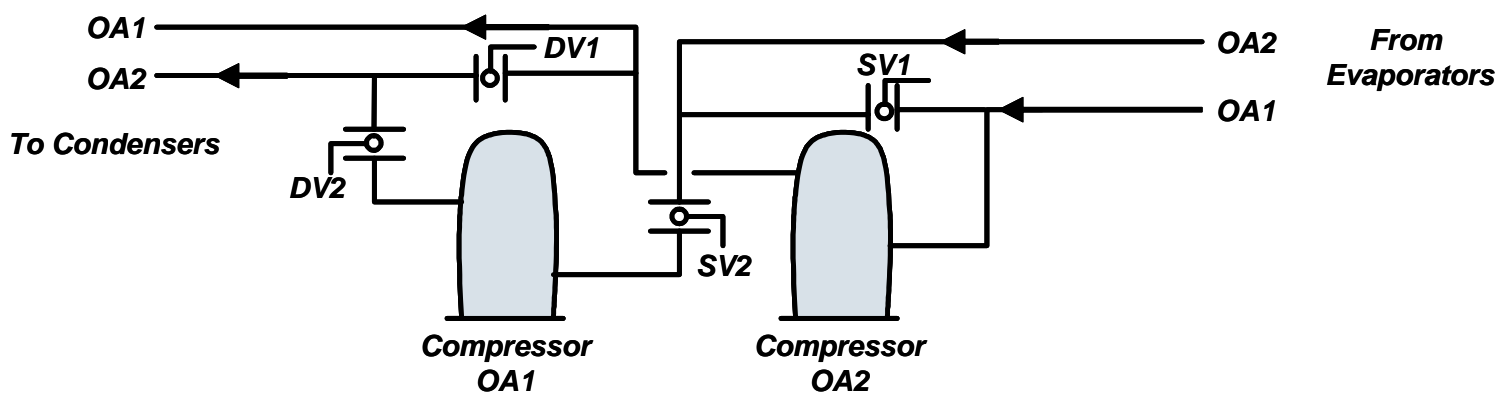

Figure 13: Outdoor Air Compressor Valves

The blower selections for the prototype are listed in Table 9 above. The blowers were arranged for belt drive operation to simplify packaging. The return blower and its motor were mounted on the furnace box, and the outdoor blower motor was mounted on the blower housing (see Figure 14 below). The belt-drive ratios for both blowers were 1:1. Motor sizes for the blowers were $3 \mathrm{hp}$ for the return blower and $1.5 \mathrm{hp}$ for the outdoor blower. The blower motors were sized so that the blowers could be operated to deliver up to 2 in wc external static pressure.

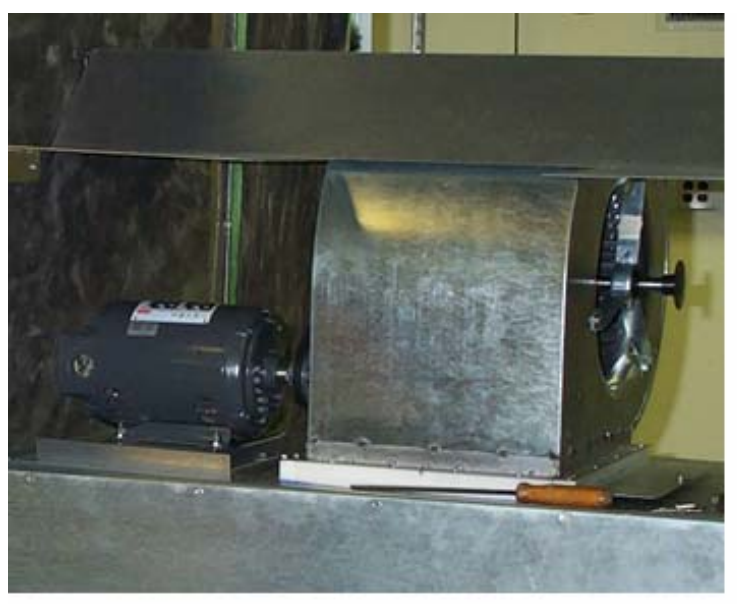

Return Blower

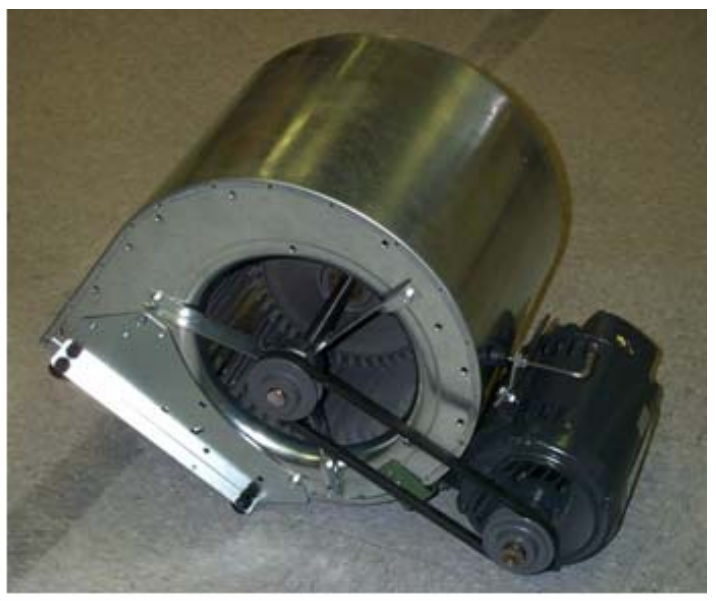

Outdoor Blower

Figure 14: Blower and Motor Assemblies 
For the outdoor blower the motor was sized to allow operation also with the energy recovery wheel installed. The blower motors were powered through Baldor ID15J203ER variable-frequency drives.

The condenser fans used in the Carrier 48HJ012 unit were also used for the IDOAS design. These are 22 -inch nominal diameter fans with $1 / 4$-hp motors, designed to draw $7,000 \mathrm{cfm}$ of air through the condenser.

Sheet metal partitions used for the IDOAS which were not part of the baseline unit were detailed using Pro-Engineer CAD software. Detailed drawings were prepared to support fabrication of the parts in TIAX's sheet metal shop. Most of the partitions were fabricated of 0.040 " aluminized steel sheet.

Three dampers were installed in the unit to provide air flow control. The dampers and their design are described below.

- Return blower discharge damper: This damper is closed when the return blower is not operating to prevent outdoor air blown into the furnace box from passing back through the return side of the unit. Investigation of damper options showed that the height of most multiple-blade damper assemblies was excessive for the height limitations of the prototype. Instead, a guillotine damper was custom-built. The damper, shown in Figure 15 below consists of a plastic frame and blade guide, the sheet metal blade, and an actuation rod, which extends through the wall of the unit to allow manual actuation from the unit exterior.

- Outdoor air throttling damper: This damper can be used to throttle flow of outdoor air to prevent increase in outdoor air flow when the return blower stops. An off-theshelf single-blade damper was selected. The damper has a two-position actuator which drives in one direction and has a spring return. The damper was mounted in a dividing wall between the outdoor air evaporator and the outdoor blower. In Figure 16 below, the damper location is shown in the dividing wall (the outdoor blower is not yet installed in front of the wall).

- Return air bypass damper: This damper provides an alternative to outdoor air throttling in order to control flow of outdoor air when the return blower stops operating. A set of three holes was made in the plenum wall dividing the return and outdoor compartments in a location between the evaporators and the throttling damper. A hinged damper closes off these holes during normal operation and is opened manually from the outside of the unit to a desired position which allows the appropriate amount of return air to mix with the outdoor air on the way to the outdoor blower inlet. 


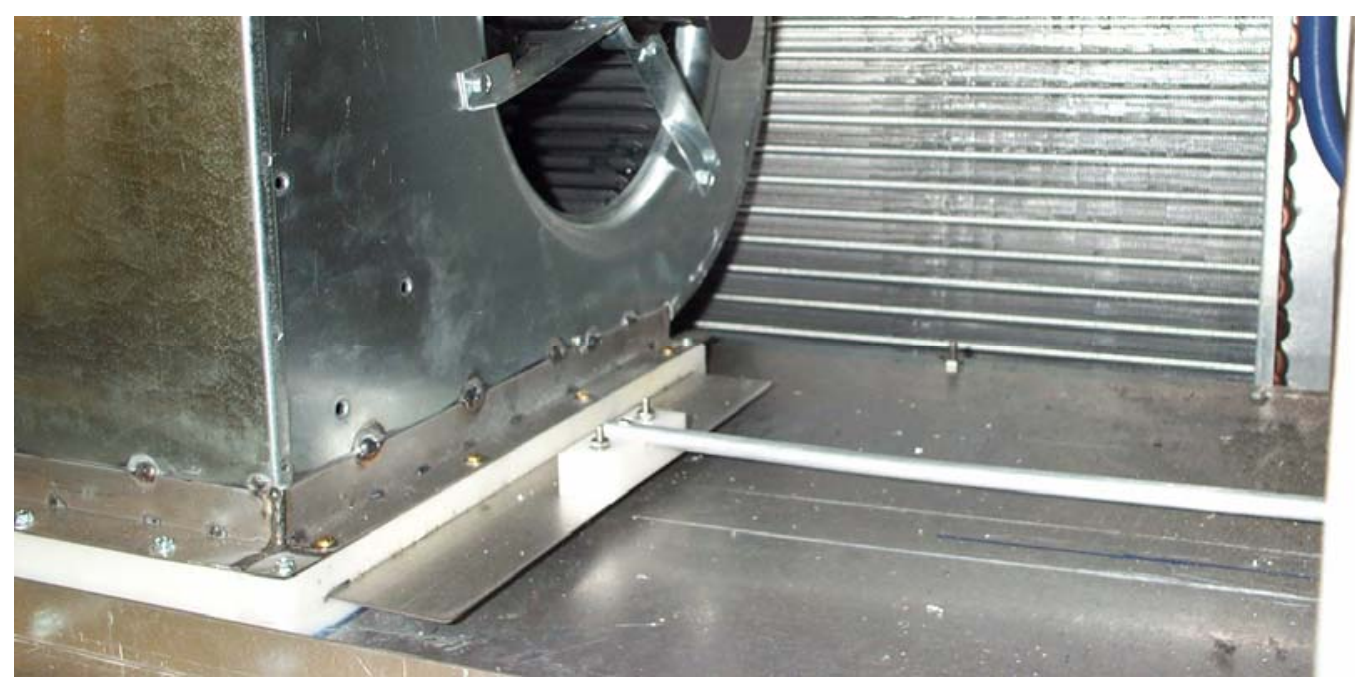

Figure 15: Return Blower Discharge Damper

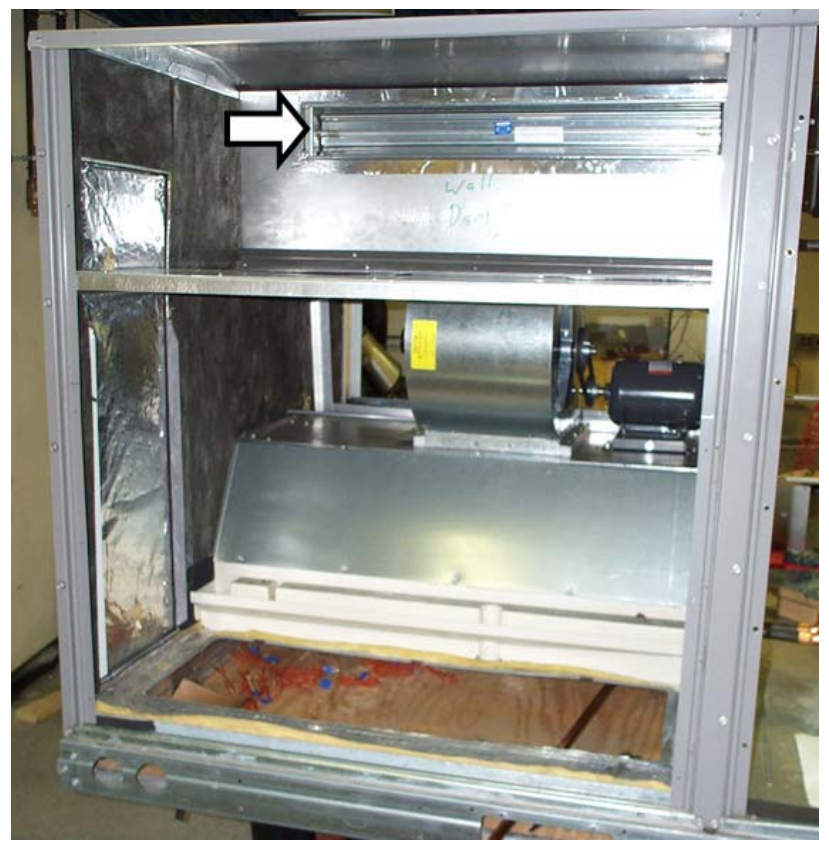

Figure 16: Outdoor Air Throttling Damper

Control for the IDOAS prototype was provided with an Allen Bradley Programmable Logic Controller (PLC). This approach was adopted in order to maintain maximum flexibility for implementing control in the future, in particular in the event of carrying out a field test during the program. Control interface with the control system was with manual switches during laboratory testing. The PLC and other electric components are shown in Figure 17 below. Additional description of the controls is provided in Appendix 1 (Section 7).

The electric panel is mounted on the dividing wall between the evaporator and condenser sections. However, the PLC is mounted with a hinged bracket that allows it to be pivoted such that the PLC user interface is accessible from outside the unit during unit operation. 


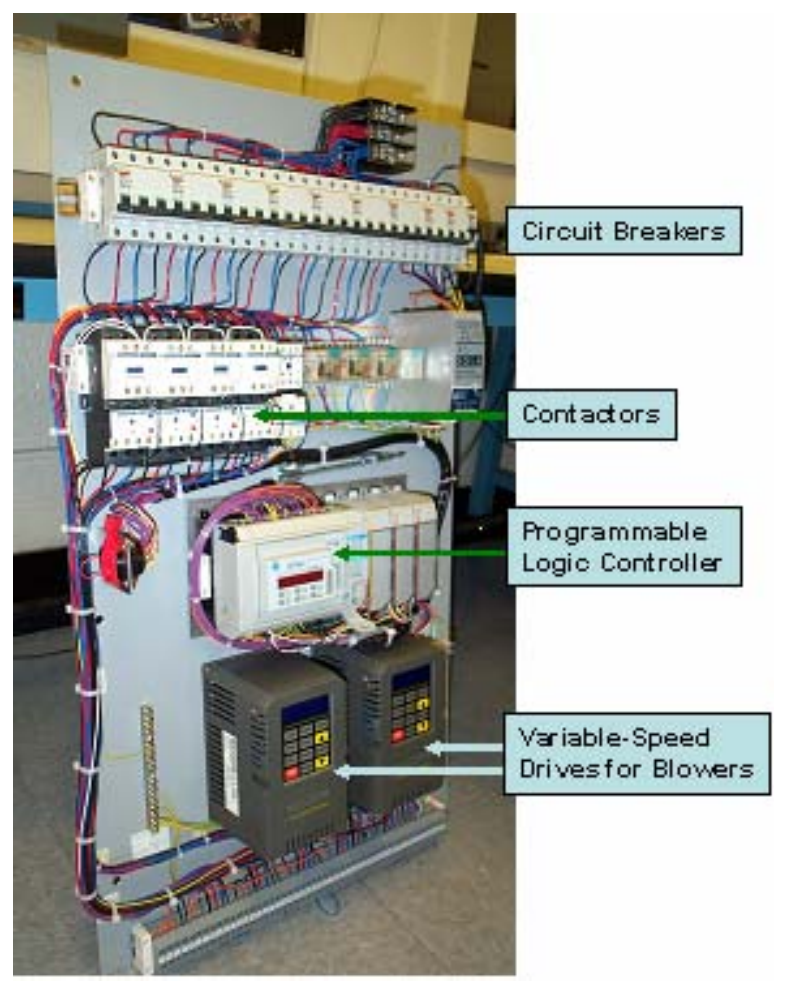

Figure 17: Electric Panel

As mentioned above, the IDOAS unit was fabricated on the chassis of a dismantled Carrier 48HJ012. Assembly of the unit was done in TIAX's shop. Fabrication of sheet metal partitions was done in TIAX's sheet metal shop. Refrigerant piping was prepared, brazed, and leak-checked by TIAX technician staff. The completed IDOAS prototype is shown in Figure 18 below.

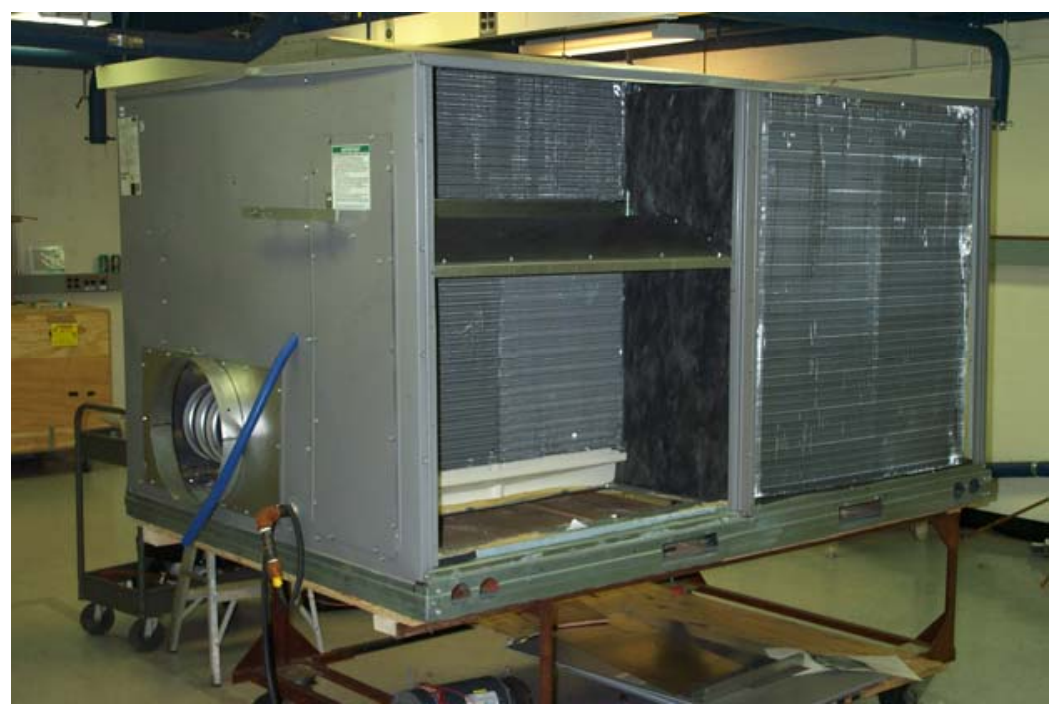

Figure 18: Completed IDOAS Prototype 
An AirXChange total energy recovery wheel was selected for use for the energy recovery module. The model ERC-3623-03 was selected. This wheel has a 36-inch diameter and has a 1 in wc pressure drop for 2,300 scfm air flow. The energy recovery module was designed to mount on the outdoor air intake portion of the IDOAS unit. The energy recovery wheel package is shown partially assembled in Figure 19 below.

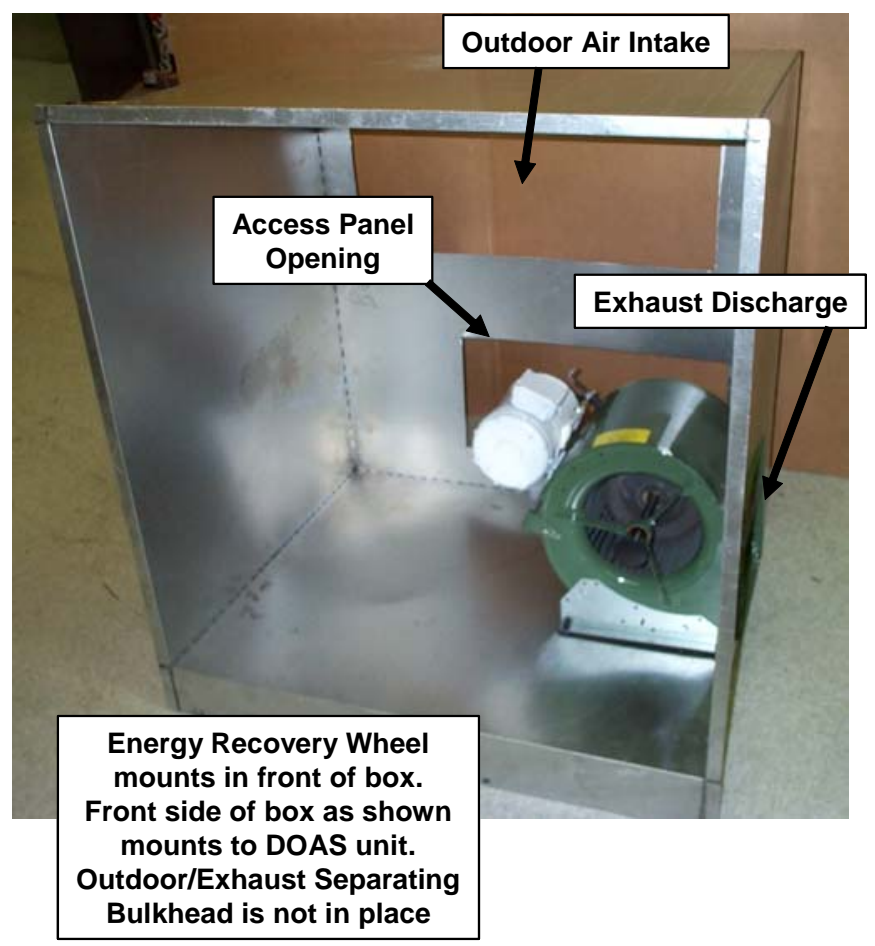

Figure 19: Energy Recovery Wheel Assembly (Partially Assembled) 


\section{Prototype Testing}

\subsection{Summary}

Performance testing for this project was done in the TIAX air-conditioner test facility, shown in Figure 20 below. The facility, set up for testing of air-conditioning units consistent with ASHRAE Standard 37, has been modified during the course of this project to allow performance testing for the IDOAS unit, which has two inlet air streams which must be controlled. More description of the facility is provided in Section 4.2.

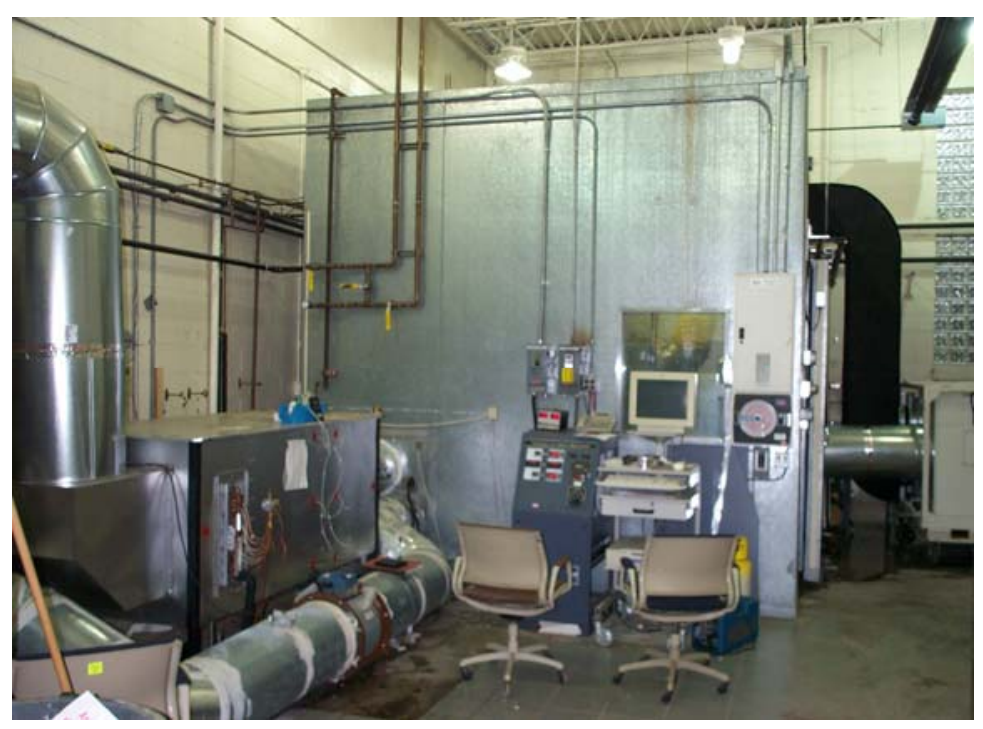

Figure 20: TIAX Air-Conditioner Test Facility

The following test work was carried out during the course of the project.

Baseline unit testing: Carrier donated a 48HJ012 rooftop unit to be converted into the IDOAS prototype. We tested the performance of this baseline unit at ARI capacity rating conditions prior to conversion of the unit.

ARI Rating Condition Test: The IDOAS unit was first tested in conditions representative of ARI rating conditions. This test was carried out with return air and outdoor air entering conditions representative of actual unit operation (i.e. warm moist outdoor air and cool dry return air), but such that the mixed air condition would have been consistent with the $80^{\circ} \mathrm{F}$ dry bulb / $67^{\circ} \mathrm{F}$ wet bulb used for the capacity test.

Off-design testing in standard configuration: The unit was tested under a series of ambient conditions and compressor run combinations representing off-design operation. This was done for the unit for single-speed operation without the energy recovery wheel integrated with the unit. The conditions selected for the tests span the range of conditions important for cooling-season operation, including wide variations in both ambient temperature and humidity. Operating states (i.e. combinations of compressors and 
blowers which operate) were selected based on examination of the modeling results for each given ambient condition. For each condition, a combination of operating states was chosen which would result in total capacities and sensible heat ratios which would bound the space requirements as modeled. This allowed analysis providing estimates of weighted average energy use for each ambient condition which could be compared with the models.

Half-air-flow testing: Additional tests were performed while operating the unit with half the return air, which would represent modulation of air flow in a VAV configuration. The half-flow operating states corresponded to states in which one of the two return compressors was operating.

ERW Testing: Finally, testing was done with the energy recovery wheel module attached to the unit. One of the key objectives of this test was to determine whether the use of the energy recovery wheel would allow elimination of one of the two outdoor compressors. These tests were carried out with the single operating circuit working with just its own evaporator and condenser circuits, and also with the flow switching valves configured so that both sets of outdoor evaporator circuits and condenser circuits were being used (see Figure 13 in Section 3).

\subsection{Test Facility and Instrumentation}

The test facility is set up to allow testing consistent with ASHRAE Standard 37. The airconditioning unit is placed in an environmental chamber which is controlled to maintain internal temperature at the desired ambient test temperature. Evaporator air is ducted to an enthalpy loop in which the air flow rate and entering and leaving temperature and humidity are measured. Addition of sensible heat and steam in this loop allows conditioning the returning air to the desired unit return air temperature and humidity.

Modifications to the enthalpy loop were made during the course of the project to allow proper testing of the dual air flow path arrangement of the IDOAS design. The test facility arrangement during IDOAS testing is shown in Figure 21 below. The outdoor air loop was installed in order to allow further conditioning of the air to the temperature and humidity desired for the ambient air. For some part-load operating conditions, the supply temperature and/or absolute humidity was higher than that specified for the return air. To allow conditioning the air to the desired return air condition, it was necessary to install a cooling coil in the enthalpy loop ducting. Cooling was provided by a 5-ton residential condensing unit.

Additional modifications were made to the test facility in order to allow testing of the unit with the ERW module attached. The configuration for these tests is shown in Figure 22 below. The split of air to serve the outdoor loop was made within the unit rather than outside the unit. This allowed use of some of the return air entering the unit to be used as exhaust air to regenerate the energy recovery wheel. For these tests, the exhaust blower had to provide sufficient pressure to move the air through the outdoor air loop, rather than just enough pressure to account for the energy recovery wheel. Thus, power 
measurements of the unit during ERW configuration testing had to be adjusted for the excess power associated with this additional load on the blower.

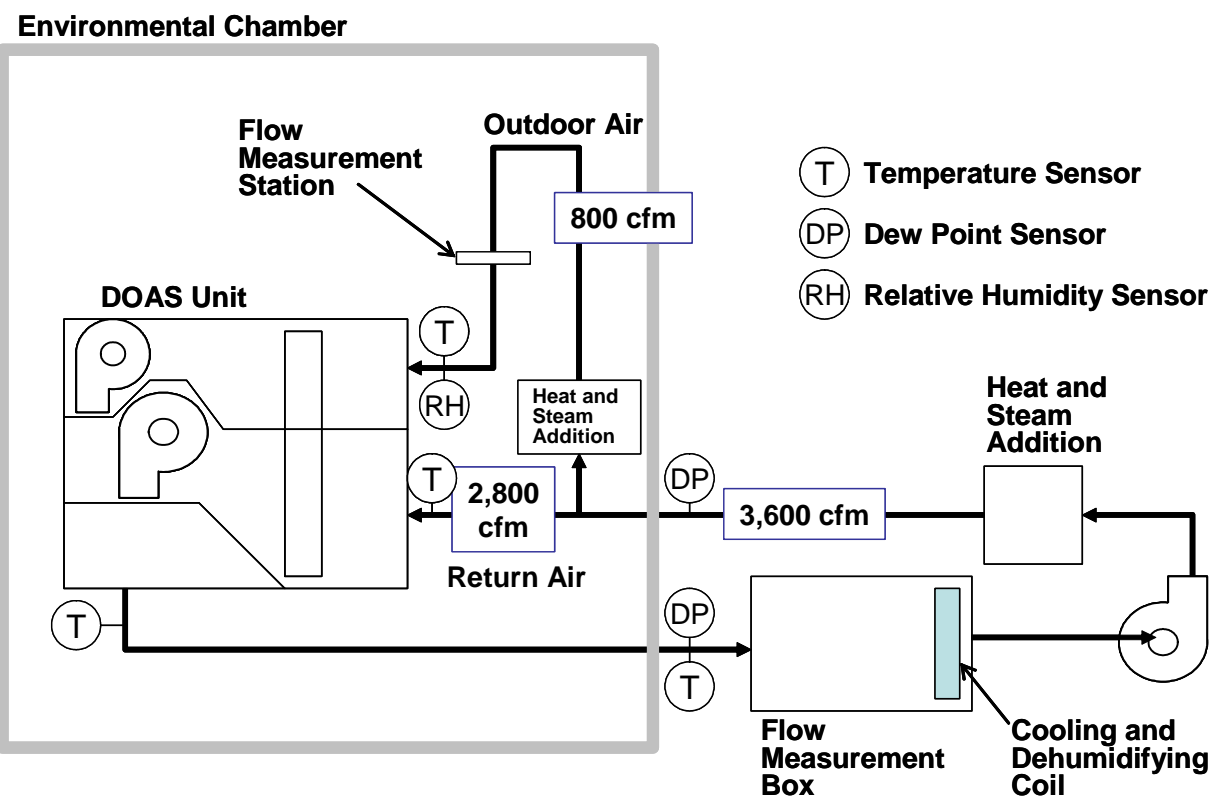

Figure 21: Test Facility for IDOAS Testing without Energy Recovery Wheel

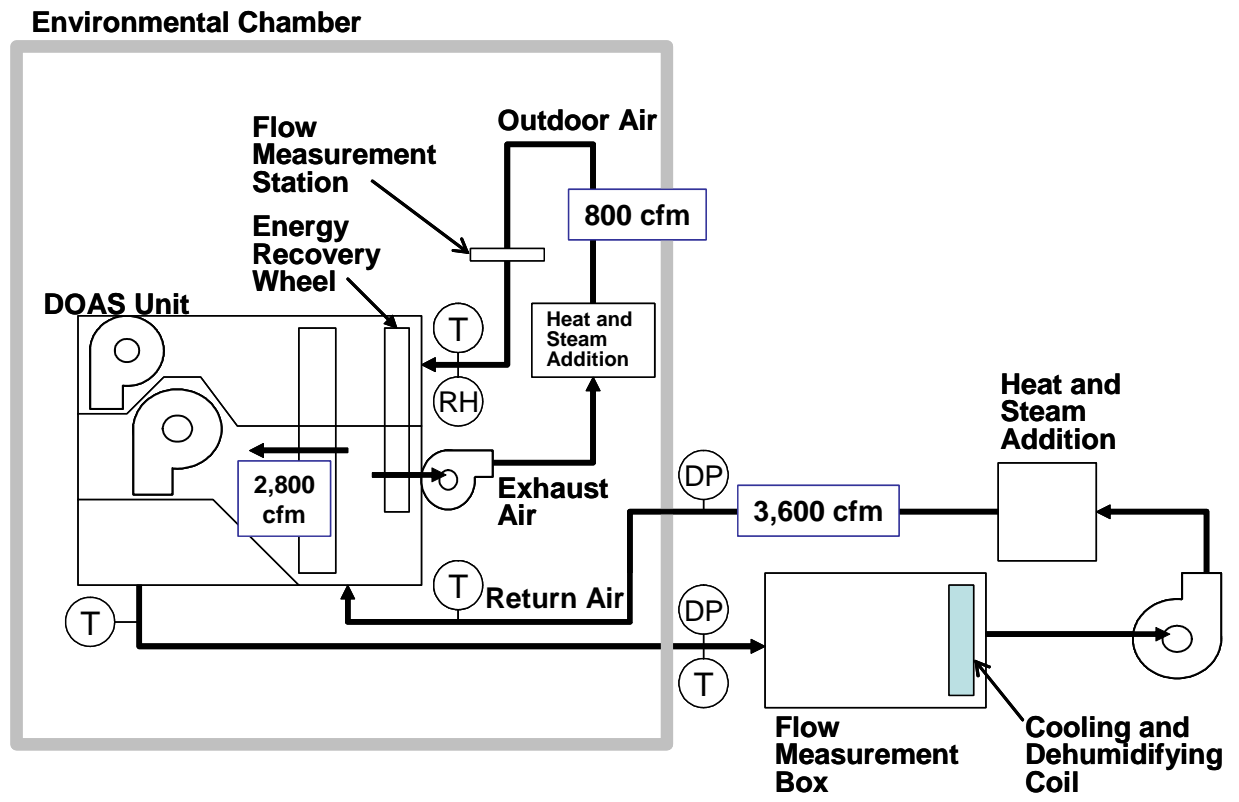

Figure 22: Test Facility for IDOAS Testing with Energy Recovery Wheel

Measurements made in the test facility are summarized in Table 10 below. 
Table 10: Integrated DOAS Test Facility Measurement Summary

\begin{tabular}{|c|c|c|c|}
\hline Type & Location(s) & \begin{tabular}{|l} 
Purpose \\
\end{tabular} & Measurement Device \\
\hline Air Flow & Main Loop & \begin{tabular}{|l} 
Capacity \\
Measurement
\end{tabular} & $\begin{array}{l}\text { Air flow measurement box with } \\
\text { four (4) flow nozzles of 6-inch } \\
\text { nozzle diameter, Differential } \\
\text { pressure measurement with } \\
\text { Dwyer Series } 475 \text { digital } \\
\text { manometer }\end{array}$ \\
\hline Air Flow & Outdoor Air Loop & \begin{tabular}{|l|} 
Capacity \\
Measurement
\end{tabular} & $\begin{array}{l}\text { Tek-Air Systems VT Air Flow } \\
\text { Sensor. }\end{array}$ \\
\hline $\begin{array}{l}\text { Air } \\
\text { Temperature }\end{array}$ & $\begin{array}{l}\text { Enthalpy Loop } \\
\text { including Outdoor } \\
\text { Air branch. }\end{array}$ & \begin{tabular}{|l|} 
Capacity \\
Measurement
\end{tabular} & $\begin{array}{l}\text { Type T Thermocouples. } \\
\text { Multiple measurements taken at } \\
\text { all locations. }\end{array}$ \\
\hline Air Humidity & Main Loop & \begin{tabular}{|l|} 
Capacity \\
Measurement
\end{tabular} & $\begin{array}{l}\text { General Eastern Dew-10 } \\
\text { Dewpoint Sensor }\end{array}$ \\
\hline Air Humidity & Outdoor Air Loop & \begin{tabular}{|l|} 
Capacity \\
Measurement
\end{tabular} & $\begin{array}{l}\text { Vaisala HMP } 233 \\
\text { Temperature/Humidity Sensor }\end{array}$ \\
\hline Air Pressures & $\begin{array}{l}\text { Enthalpy Loop } \\
\text { including Outdoor } \\
\text { Air branch. }\end{array}$ & $\begin{array}{l}\text { Setting operating } \\
\text { conditions. }\end{array}$ & $\begin{array}{l}\text { Dwyer Series } 475 \text { digital } \\
\text { manometer. }\end{array}$ \\
\hline $\begin{array}{l}\text { Air } \\
\text { Temperature }\end{array}$ & $\begin{array}{l}\text { Condenser Air } \\
\text { Inlet }\end{array}$ & \begin{tabular}{|l|} 
Control of \\
Environmental \\
Chamber, \\
Assurance of \\
Temperature \\
Uniformity
\end{tabular} & $\begin{array}{l}\text { Type T Thermocouples. }{ }^{1} \text { Nine } \\
\text { measurements over condenser } \\
\text { surface. }\end{array}$ \\
\hline $\begin{array}{l}\text { Refrigerant } \\
\text { Pressures }\end{array}$ & All Circuits & \begin{tabular}{|l} 
Check of operation \\
\end{tabular} & $\begin{array}{l}\text { Heise PM-1 digital pressure } \\
\text { gauge. }\end{array}$ \\
\hline $\begin{array}{l}\text { Refrigerant } \\
\text { Temperatures }\end{array}$ & \begin{tabular}{|l|} 
All Circuits: \\
Evaporator exit, \\
compressor \\
suction, \\
compressor \\
discharge, \\
condenser exit \\
\end{tabular} & Check of operation & $\begin{array}{l}\text { Type T Surface } \\
\text { Thermocouples. }{ }^{1} \text { Piping } \\
\text { insulated in location of } \\
\text { thermocouple. }\end{array}$ \\
\hline $\begin{array}{l}\text { Electric } \\
\text { Power }\end{array}$ & $\begin{array}{l}\text { System total power } \\
\text { input. }\end{array}$ & EER Measurement & $\begin{array}{l}\text { Yokagowa WT130 Power } \\
\text { Meter set up with 12:1 Omega } \\
\text { RCT151605A current } \\
\text { transducers. }^{2}\end{array}$ \\
\hline
\end{tabular}

Notes:

1. Measurements of thermocouple voltage made with Agilent 34970A dataloggers.

2. Power measurements were also separately made with same-model Yokagowa Power Meters without current transducers for the outdoor blower and the energy recovery wheel exhaust blower. 


\subsection{Baseline Unit Testing}

Carrier provided a baseline 48HJ012 conventional rooftop unit for this project. This is a 10-ton 11-EER unit. The unit's chassis was used for fabrication of the IDOAS prototype. Prior to conversion of the unit, capacity testing of this unit was carried out to verify that its performance matched the performance data published for it in Carrier literature. Results of the test are summarized in Table 11 below.

The test was carried out without adjusting the blower's pulley ratio to match the 0.2 in wc which is the standard external static pressure for test of a 10-ton unit. Instead, the blower power and capacity were adjusted to reflect the fact that the unit was providing more pressure.

The test data provide a validation of the TIAX test facility. The measured capacity and power input match the literature data very closely. Furthermore, latent capacity estimates based on different measurements agree very closely.

Table 11: Baseline Unit Performance Test Data

\begin{tabular}{|l|c|c|c|}
\hline & test result & $\begin{array}{c}\text { results } \\
\text { adjusted for } \\
0.2 \text { " w.c. }\end{array}$ & $\begin{array}{c}\text { Carrier product data } \\
\text { literature; ARI conditions }\end{array}$ \\
\hline total capacity [kBtuh] & 117.9 & 119.1 & 119.3 \\
\hline sensible capacity [kBtuh] & 79.9 & 81.1 & 82.0 \\
\hline $\begin{array}{l}\text { latent capacity [kBtuh] based on } \\
\text { condensate collection }\end{array}$ & 37 & 37 & 39.9 \\
\hline $\begin{array}{l}\text { latent capacity [kBtuh] based on } \\
\text { dew pt for entering \& leaving air }\end{array}$ & 39 & 39 & 39.9 \\
\hline EER & 10.2 & 10.6 & 11.0 \\
\hline total power [kW] & 11.6 & 11.2 & 10.9 \\
\hline compressor motor power [kW] & 9.6 & 9.6 & 9.2 \\
\hline both condenser fans power [W] & 600 & 600 & 650 \\
\hline indoor fan power [W] & 1320 & 956 & 764 \\
\hline
\end{tabular}




\section{4. $\quad$ ARI Rating Point Testing}

Initial testing of the IDOAS prototype was done at ARI capacity rating conditions. However, there is no ARI standard which covers testing of a unit with a separate outdoor air flow path and evaporator. While Standard ARI 210/240-2005 Unitary AirConditioning and Air-Source Heat Pump Equipment, which covers capacities up to 135,000 Btu/hr, would be applicable for 10-ton rooftop units, performance measurements anticipated by this standard involve only a single air stream returning to the unit. Standard ARI 340/360 Commercial and Industrial Unitary Air-Conditioning and Heat Pump Equipment, which covers capacities above 135,000 Btu/hr, has allowance for testing a unit in which a separate outdoor coil precools the outdoor air prior to mixing with the return air upstream of the main cooling coil. However, the IDOAS has separate treatment of both air streams with no mixing prior to blower discharge. Hence an approach based on the ARI Standard rating capacity was developed.

For the IDOAS ARI test, the operating conditions which are clearly specified in Standard ARI 210/240 are used. These include the outdoor temperature and wet bulb temperature: $95^{\circ} \mathrm{F}$ dry bulb / $75^{\circ} \mathrm{F}$ wet bulb. Since the IDOAS unit operates with outdoor and return air entering the unit separately, the outdoor air was adjusted to $95^{\circ} \mathrm{F} \mathrm{DB} / 75^{\circ} \mathrm{F} \mathrm{WB}$. The return condition was adjusted to $75^{\circ} \mathrm{F}$ and $50 \% \mathrm{RH}$, which is typical for indoor conditions during the cooling season. The mixed-air conditions were very close to the $80^{\circ} \mathrm{F} \mathrm{DB} / 67^{\circ} \mathrm{F}$ WB (Absolute humidity ratio of $0.0112 \mathrm{lb} / \mathrm{lb}$ dry air) specified for the return in the conventional ARI standard. The prototype was tested under ARI capacity test conditions at two return air flow rates. For the low-air-flow test, the calculated mix conditions were $80.0^{\circ} \mathrm{F} / 0.0117 \mathrm{lb} / \mathrm{lb}$ dry air and for the high-air-flow test they were $80.0^{\circ} \mathrm{F} / 0.0115 \mathrm{lb} / \mathrm{lb}$ dry air.

The ARI capacity test results are summarized in Table 12 below. Detailed data for the tests are tabulated in Appendix 2 (Section 8). The table also shows model results and performance of the conventional baseline unit. The final two columns in the table represent model data, first for the IDOAS as calculated during the initial phase of the project, and also for the baseline conventional rooftop unit. Model data is shown for the conventional unit rather than literature performance data or measured data, since the model data compares more consistently with the IDOAS model data. Actual EER for the conventional unit is 11 .

The IDOAS prototype unit has capacity less than expected and power input greater than expected. Its sensible heat ratio (SHR) is equal to that of the conventional rooftop unit when operating at the lower air flow rate-total air flow for this condition is slightly higher than that of the conventional unit. Capacity is split fairly evenly between the outdoor and return side of the unit. Latent capacity is slanted heavily towards the outdoor air side, as expected. The different SHRs for the two parts of the unit illustrate the potential for humidity control by switching between compressors of one side versus the other. 
Table 12: IDOAS Prototype ARI Capacity Test

\begin{tabular}{|c|c|c|c|c|}
\hline Description & $\begin{array}{c}\text { IDOAS } \\
\text { Prototype } \\
\text { Low Air Flow }\end{array}$ & $\begin{array}{c}\text { IDOAS } \\
\text { Prototype } \\
\text { High Air Flow }\end{array}$ & $\begin{array}{l}\text { IDOAS Model } \\
\text { Version 2D } \\
\text { Single-Speed }\end{array}$ & $\begin{array}{c}\text { Carrier } \\
\text { 48HJ012, } \\
\text { Model }\end{array}$ \\
\hline $\begin{array}{l}\text { Air Flow }(\mathrm{scfm}) \text { : } \\
\text { OA } \\
\text { RA }\end{array}$ & $\begin{array}{c}3,257 \\
872 \\
2,385\end{array}$ & $\begin{array}{c}3,625 \\
881 \\
2,744\end{array}$ & $\begin{array}{c}3,680 \\
880 \\
2,800\end{array}$ & 3,200 \\
\hline $\begin{array}{l}\text { Entering DB }\left({ }^{\circ} \mathrm{F}\right) / \\
\text { W (lb/lb dry air): } \\
\text { OA } \\
\text { RA } \\
\text { Calculated Mix }\end{array}$ & $\begin{array}{l}94.7 / 0.0151 \\
74.7 / 0.0105 \\
80.0 / 0.0117\end{array}$ & $\begin{array}{l}95.4 / 0.0148 \\
75.1 / 0.0105 \\
80.0 / 0.0115\end{array}$ & $\begin{array}{c}95 / 0.015 \\
75 / 0.0093\end{array}$ & $80 / 0.0112$ \\
\hline $\begin{array}{l}\text { Supply DB }\left({ }^{\circ} \mathrm{F}\right) / \\
\text { W (lb/lb dry air) }\end{array}$ & $60.3 / 0.0095$ & $60.6 / 0.0099$ & & \\
\hline $\begin{array}{l}\text { Capacity (Btu/hr): } \\
\text { OA Net } \\
\text { Sensible } \\
\text { Latent } \\
\text { SHR }\end{array}$ & $\begin{array}{c}56,945 \\
32,389 \\
24,556 \\
0.57\end{array}$ & $\begin{array}{c}55,427 \\
33,064 \\
22,362 \\
0.60\end{array}$ & & \\
\hline $\begin{array}{c}\text { RA Net } \\
\text { Sensible } \\
\text { Latent } \\
\text { SHR }\end{array}$ & $\begin{array}{c}48,354 \\
36,940 \\
11,414 \\
0.76\end{array}$ & $\begin{array}{c}51,595 \\
42,773 \\
8,822 \\
0.829\end{array}$ & & \\
\hline $\begin{array}{c}\text { Total Net } \\
\text { Sensible } \\
\text { Latent } \\
\text { SHR }\end{array}$ & $\begin{array}{c}105,299 \\
69,329 \\
35,970 \\
0.66\end{array}$ & $\begin{array}{c}107,022 \\
75,837 \\
31,184 \\
0.71\end{array}$ & $\begin{array}{c}118,200 \\
0.70\end{array}$ & $\begin{array}{c}120,100 \\
0.66\end{array}$ \\
\hline $\begin{array}{l}\text { Power (W): } \\
\text { OA Blower } \\
\text { RA Blower } \\
\text { Condenser Fans } \\
\text { Compressors } \\
\text { Miscellaneous } \\
\text { Total }\end{array}$ & $\begin{array}{c}400 \\
980 \\
600 \\
9,650 \\
20 \\
11,650\end{array}$ & $\begin{array}{c}400 \\
1,580 \\
600 \\
9,650 \\
20 \\
12,250\end{array}$ & $\begin{array}{c}200 \\
400 \\
600 \\
9,400 \\
- \\
10,600\end{array}$ & $\begin{array}{c}764 \\
600 \\
9,208 \\
- \\
10,572\end{array}$ \\
\hline EER & 9.04 & 8.94 & 11.2 & 11.36 \\
\hline
\end{tabular}

Note: Separate performance breakout for the outdoor and return circuits for the prototype are approximations, since they are based on the assumption that each circuit conditions its air stream to the supply air conditions.

The performance of the prototype is not consistent with expectations largely because of deficiencies in component performance, including the following.

- Heat exchangers not performing as expected. The average condensing temperature of the prototype is $3.2^{\circ} \mathrm{F}$ higher than the modeled condenser performance. Average evaporating temperature for the upstream circuits of both evaporators is $1^{\circ} \mathrm{F}$ lower. The evaporating temperatures of the downstream evaporator circuits do not provide a good basis of comparison because the reduced capacity of the upstream circuits increases air entering temperature for the downstream circuits and hence also their evaporating temperature. The higher condensing temperatures in particular reduce capacity and increases input power. 
- Compressors not performing according to their performance maps. Based on a comparison of air conditioner capacity and performance predictions for actual operating pressures and heat exchanger exit temperatures, capacity of the compressors is about $4 \%$ low and power input is about $5 \%$ high.

- High blower power due to our attempts to fit the blowers into the existing package size. We have conservatively estimated that blower power savings would be $450 \mathrm{~W}$ for the return blower and 150W for the outdoor blower.

If it is assumed that the heat exchangers were performing as modeled, the blower wattages could be reduced by the values indicated above, and the compressor power input was reduced by the excess 5\% (without also assuming that the compressors deliver their advertised capacity), the EER of the unit would be increased to 10.7. Further changes could be made to improve further upon this, for example, a 0.5 EER increase could be achieved through the use of 24-inch rather than 22-inch diameter condenser fans. However, the focus of the project is to show that good performance can be achieved over a wide range of operating conditions.

\subsection{Off-Design Testing}

Off-design testing of the unit was done to assess performance of the IDOAS prototype for a range of key cooling season conditions. A group of ambient conditions which are representative of the range of cooling season conditions were chosen. The expected operating states of the IDOAS for these ambient conditions were determined based on examination of the modeling results. For instance, for extreme hot conditions, it is expected that the unit will operate at $100 \%$ capacity. For moderate conditions, a range of operational configurations is expected from full to part load. For cool conditions, it is not expected that more than one or two compressors would be operating at a given time. The ambient humidity level would also provide an indication of whether the return air or outdoor air circuit compressors would be operating. The selected ambient conditions are shown in Figure 23 below. Points numbered 2 and 5 have been omitted as the selection

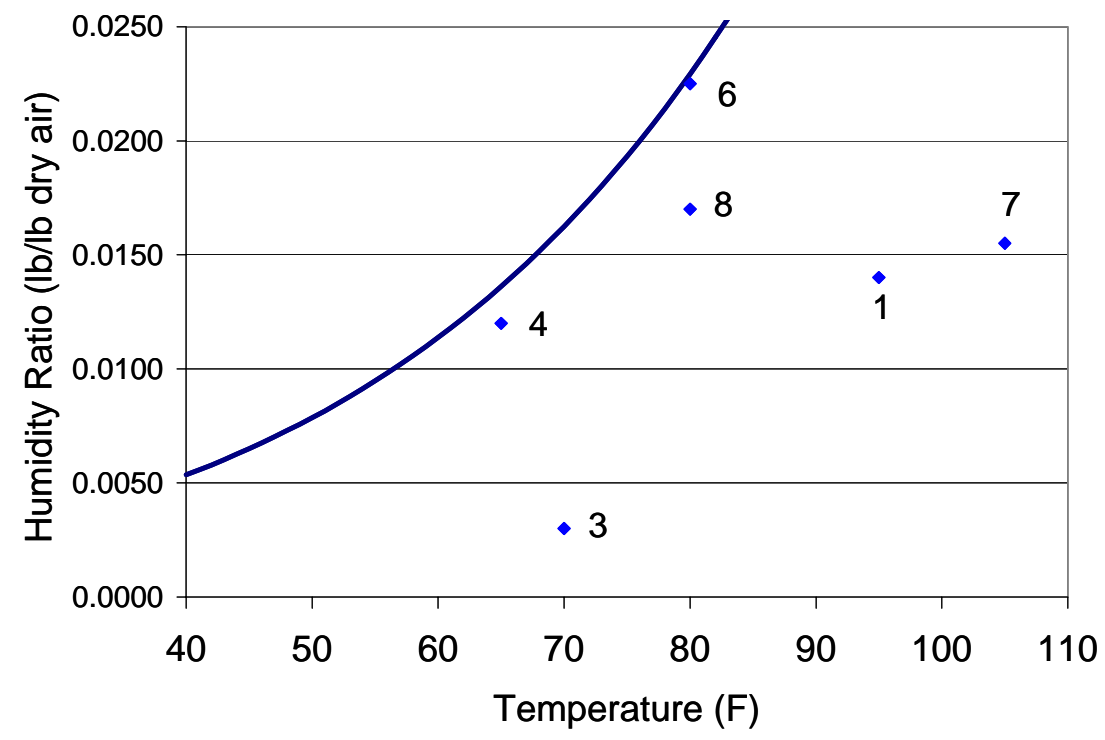

Figure 23: Off-Design Testing Ambient Conditions 
of points evolved. The IDOAS prototype operating configurations for off-design testing with $100 \%$ return air flow rate are listed in Table 13 below.

Table 13: Off-Design Testing Operating Configurations-Full Air Flow

\begin{tabular}{|c|c|c|c|c|c|}
\hline 㤩总总 & 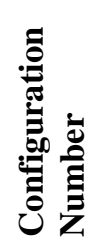 & 壱 & 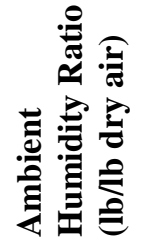 & 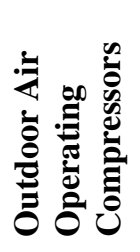 & 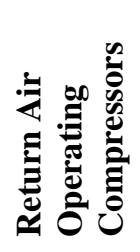 \\
\hline \multirow[t]{3}{*}{1} & 1 & \multirow[t]{3}{*}{95} & \multirow[t]{3}{*}{0.0140} & 2 & 1,2 \\
\hline & 2 & & & 1,2 & 1,2 \\
\hline & 3 & & & 1 & 1,2 \\
\hline \multirow[t]{2}{*}{3} & 1 & \multirow[t]{2}{*}{70} & \multirow[t]{2}{*}{0.003} & 1 & Off \\
\hline & 2 & & & 2 & $\overline{\text { Off }}$ \\
\hline \multirow[t]{3}{*}{4} & 1 & \multirow[t]{3}{*}{65} & \multirow[t]{3}{*}{0.012} & 1 & $\overline{\text { Off }}$ \\
\hline & 2 & & & 2 & Off \\
\hline & 3 & & & 1,2 & $\overline{\text { Off }}$ \\
\hline \multirow[t]{4}{*}{6} & 1 & \multirow[t]{4}{*}{80} & \multirow[t]{4}{*}{0.0225} & 1,2 & Off \\
\hline & 2 & & & 1,2 & 1,2 \\
\hline & 3 & & & 1,2 & 1 \\
\hline & 4 & & & 1,2 & 2 \\
\hline 7 & 1 & 105 & 0.0155 & 1,2 & 1,2 \\
\hline \multirow[t]{6}{*}{8} & 1 & \multirow[t]{6}{*}{80} & \multirow[t]{6}{*}{0.017} & 1,2 & 1,2 \\
\hline & 2 & & & 1,2 & Off \\
\hline & 3 & & & 1,2 & 1 \\
\hline & 4 & & & 1,2 & 2 \\
\hline & 5 & & & 1 & 1,2 \\
\hline & 6 & & & 2 & 1,2 \\
\hline
\end{tabular}

Additional testing was done for some of the conditions to reflect operation of a VAV system. These tests were done with the return air flow at half flow for configurations for which only one of the return air compressors was operating. These operating configurations are listed in Table 14 below.

Table 14: Off-Design Testing Operating Configurations-Half Air Flow

\begin{tabular}{|c|c|c|c|c|c|}
\hline 䒿总总 & 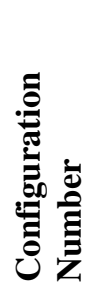 & 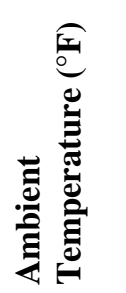 & 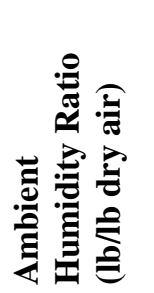 & 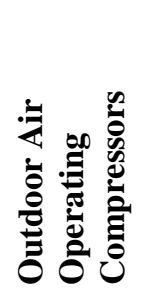 & 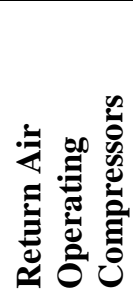 \\
\hline 3 & 3-vav & 70 & 0.0030 & Off & 2 \\
\hline 8 & $\begin{array}{l}3 \text { 3-vav } \\
4 \text {-vav }\end{array}$ & 80 & 0.0170 & $\begin{array}{l}1,2 \\
1,2\end{array}$ & $\begin{array}{l}1 \\
2 \\
\end{array}$ \\
\hline
\end{tabular}


Detailed data for all of these test conditions are tabulated in Appendix 2 (Section 8). Capacity data for the unit for full-air-flow operation is illustrated in Figure 24 below. The plot shows the variation in sensible heat ratio which is achieved with the IDOAS design as different combinations of compressors are operating.

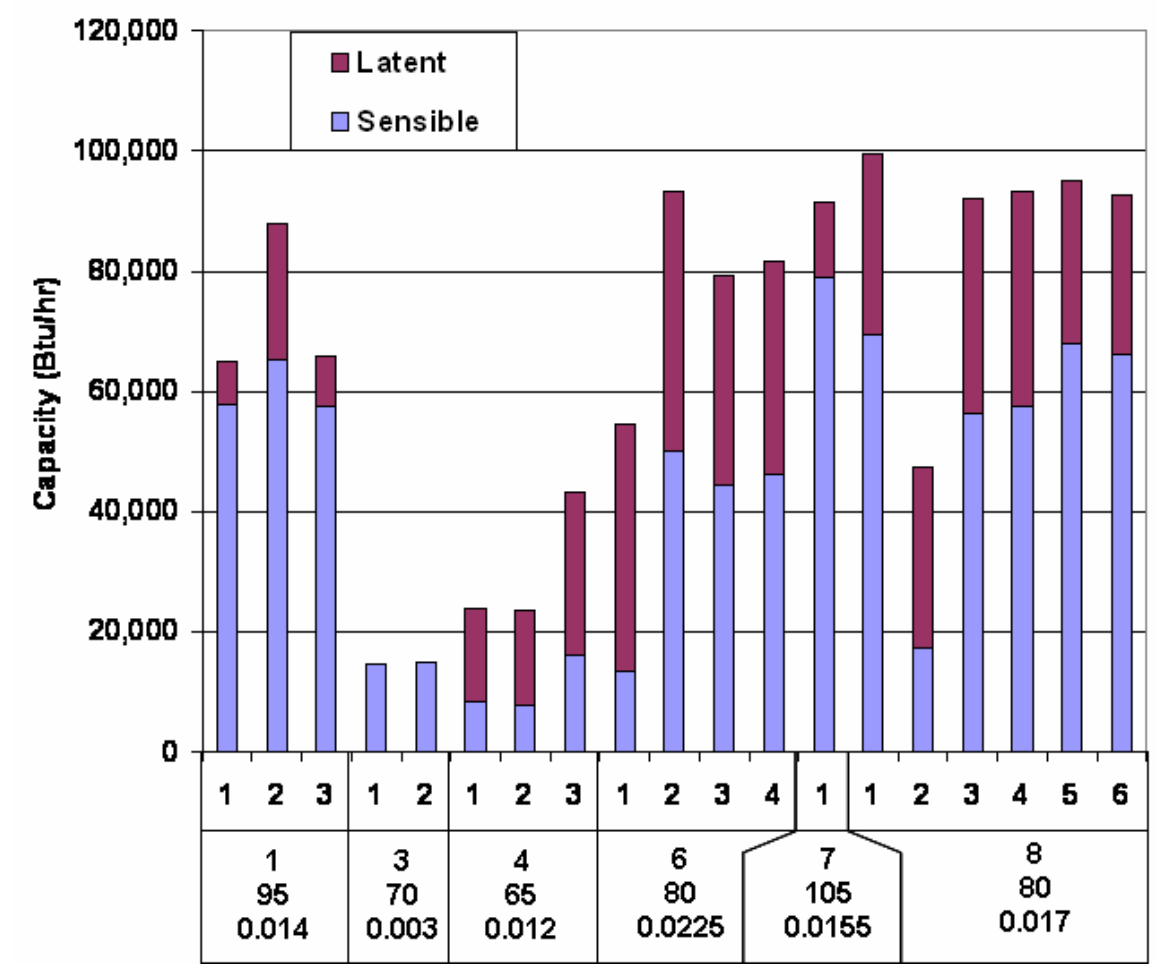

Figure 24: IDOAS Prototype Capacity Data for Full-Flow Off-Design Testing

Analysis of the full-air-flow test data was done to assess ability to satisfy the desired space conditions and to calculate average energy use as the unit cycles between operating configurations. For each ambient condition, the combination of operating configurations was determined which best matches the desired space conditions with minimum energy input. This is illustrated in Table 15 below for four of the ambient conditions.

Table 15: Illustration of Off-Design Cycling to Satisfy Desired Space Conditions

\begin{tabular}{|c|c|c|c|c|c|c|c|c|c|c|c|c|c|}
\hline & & & & \multicolumn{2}{|c|}{ Compressors } & & & & & & & & \\
\hline $\begin{array}{l}\text { OA } \\
\text { No }\end{array}$ & $\begin{array}{l}\text { Case } \\
\text { No }\end{array}$ & $\begin{array}{l}\text { OA } \\
\text { DB } \\
\text { (F) }\end{array}$ & $\begin{array}{l}\text { OA HR } \\
\text { (lb/lb) }\end{array}$ & Outdoor & Return & $\begin{array}{c}\text { Required } \\
\text { Qsens } \\
\text { (Btu/hr-sqft) }\end{array}$ & $\begin{array}{c}\text { Required } \\
\text { Qlat } \\
\text { (Btu/hr-sqft) }\end{array}$ & $\begin{array}{c}\text { Delivered } \\
\text { Qsens } \\
\text { (Btu/hr-sqft) }\end{array}$ & $\begin{array}{c}\text { Delivered } \\
\text { Qlat } \\
\text { (Btu/hr-sqft) }\end{array}$ & Run Ratio & \begin{tabular}{|c|} 
Total \\
Delivered \\
Qsens \\
(Btu/hr-sqft)
\end{tabular} & $\begin{array}{c}\text { Total } \\
\text { Delivered } \\
\text { Qlat } \\
\text { (Btu/hr-sqft) }\end{array}$ & $\begin{array}{c}\text { Average } \\
\text { Power, } \\
\text { W/sqft }\end{array}$ \\
\hline 3 & 1 & 70 & 0.0030 & 1 & Off & 1.8 & -5.8 & 4.3 & 0.0 & $0.0 \%$ & 1.8 & 0.0 & 0.42 \\
\hline & 2 & & & 2 & Off & & & 4.4 & 0.0 & $46.1 \%$ & & & \\
\hline & 3 & & & Off & Off & & & \begin{tabular}{l|l|}
-0.4 \\
\end{tabular} & 0.0 & $53.9 \%$ & & & \\
\hline 4 & 1 & 65 & 0.0120 & 1 & Off & 0.7 & 3.0 & 2.4 & 4.6 & & 0.7 & 1.9 & 0.38 \\
\hline & 2 & & & 2 & Off & & & 2.3 & 4.7 & $40.5 \%$ & & & \\
\hline & 3 & & & 1,2 & Off & & & 4.8 & 7.9 & & & & \\
\hline & 4 & & & Off & Off & & & -0.4 & 0.0 & $59.5 \%$ & & & \\
\hline 7 & 1 & 105 & 0.0155 & 1,2 & 1,2 & 24.0 & 6.7 & 23.3 & 3.7 & $100.0 \%$ & 23.3 & 3.7 & 3.89 \\
\hline 8 & 1 & 80 & 0.0170 & 1,2 & 1,2 & 16.4 & 8.0 & 20.5 & 8.8 & & 16.4 & 8.0 & 2.17 \\
\hline & 2 & & & 1,2 & Off & & & 5.1 & 8.9 & $0.0 \%$ & & & \\
\hline & 3 & & & 1,2 & 1 & & & 16.7 & 10.5 & & & & \\
\hline & 4 & & & 1,2 & 2 & & & 17.0 & 10.5 & $38.7 \%$ & & & \\
\hline & 5 & & & 1 & 1,2 & & & 20.1 & 8.0 & $49.0 \%$ & & & \\
\hline & 6 & & & 2 & 1,2 & & & 19.5 & 7.8 & & & & \\
\hline & 9 & & & Off & Off & & & \begin{tabular}{|c|}
-0.4 \\
\end{tabular} & 0.0 & $12 \%$ & & & \\
\hline
\end{tabular}


The floorspace served by the unit is selected so that the unit provides $97 \%$ of the desired sensible load for the $105^{\circ} \mathrm{F}$ ambient condition, 3,400 sqft for this calculation. For the last of the ambient conditions (\#8), both the target sensible and latent loads have been met by the unit, implying that space temperature and humidity conditions have been satisfied. Note that one of the operating conditions involves no compressor operation, thus resulting in negative cooling, which is the outdoor blower power input. A group of operating conditions is combined to provide average sensible and latent cooling and average power input. For ambient condition 7 (the $105^{\circ} \mathrm{F}$ ambient case), the unit operates $100 \%$ with all compressors running in an attempt to match the desired sensible load. For ambient conditions 3 the sensible load is met easily and no dehumidification is needed or provided (the result of the negative latent load is that the indoor relative humidity would drop below 50\%. For condition 4, very little sensible or latent cooling is required. If the sensible load is met, the small shortfall in latent cooling would result in a small increase in relative humidity above 50\%. Alternatively, the latent load could be met while overcooling the space a small mount. Overcooling could be avoided by a small amount of reheat, as would be provided with minimal energy penalty by a liquid subcooling reheat coil, such as Carrier's MoistureMi\$er ${ }^{\mathrm{TM}}$.

A mapping of the comfort performance of the tested prototype by ambient condition is shown in Figure 25 below. The solid lines in the figure show the maximum humidity levels for which the performance model analysis shows that the given air-conditioning unit can still meet the desired 50\% relative humidity in the space. The dashed line shows the maximum humidity ratios for the Fort Worth analysis. The square data points

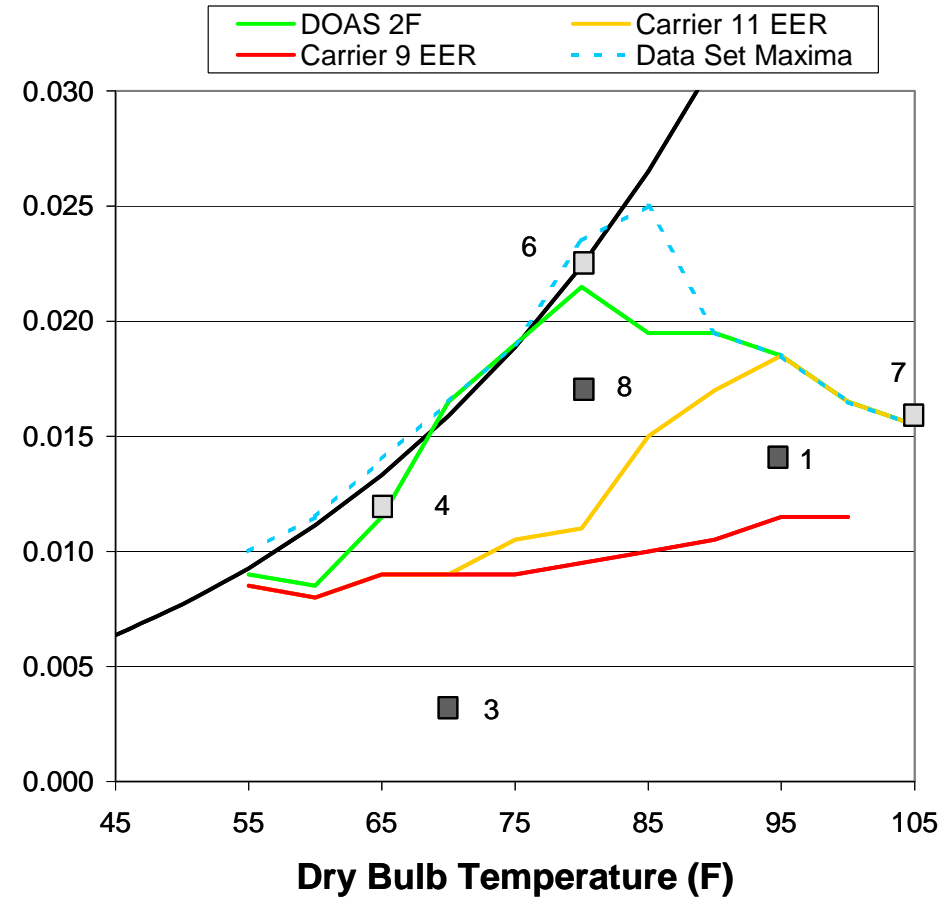

Figure 25: IDOAS Prototype Comfort Map
Test Points for which test data Indicates $50 \%$ or lower $\mathrm{RH}$ is met

Test Points for which test data Indicates greater than $50 \% \mathrm{RH}$

Missing Latent Capacity (Btu/hr-sqft)

\begin{tabular}{|c|c|c|}
\hline $\begin{array}{c}\text { Condition } \\
\text { Number }\end{array}$ & Test & $\begin{array}{c}\text { Model } \\
(2 \mathrm{D})\end{array}$ \\
\hline 4 & 1.1 & 2.1 \\
\hline 6 & 0.6 & 1.2 \\
\hline 7 & 3.0 & None \\
\hline
\end{tabular}


represent analysis using the IDOAS prototype test data. The squares shaded dark gray represent test sets for which the analysis show that the humidity condition is satisfied, and the squares shaded light gray represent tests for which the humidity condition would not be satisfied. The test data are consistent with the model predictions regarding the range of the IDOAS unit's capability of meeting desired space humidity levels.

Expected energy use calculated based on the IDOAS prototype test data is compared in Figure 26 below with modeled energy use for the IDOAS and conventional units. The conventional units include the 11 EER and 9 EER standard units and also the 11 EER unit with hot gas reheat for improved dehumidification (this is the 11EER/HGRH unit in the chart). Comparison with the hot gas reheat unit is the most relevant, because this unit can match the high level of dehumidification which can be achieved by the DOAS design, while the other conventional units operate with a large number of cooling season hours with space relative humidity above the target 50\%. Comparison is also made with an adjusted prototype which represents a unit for which some of the performance issues of the prototype identified above in Section 4.4 have been resolved. This estimate is based on the following reasonable improvements to component performance, which would boost system EER to 10.7:

- Compressors operate without the observed $4.8 \%$ excess power.

- OA blower power reduction of 150W, RA blower reduction of 450W.

- Heat Exchanger Improvement: Gross Capacity increase of 2\%, and compressor power reduction of $5.2 \%$.

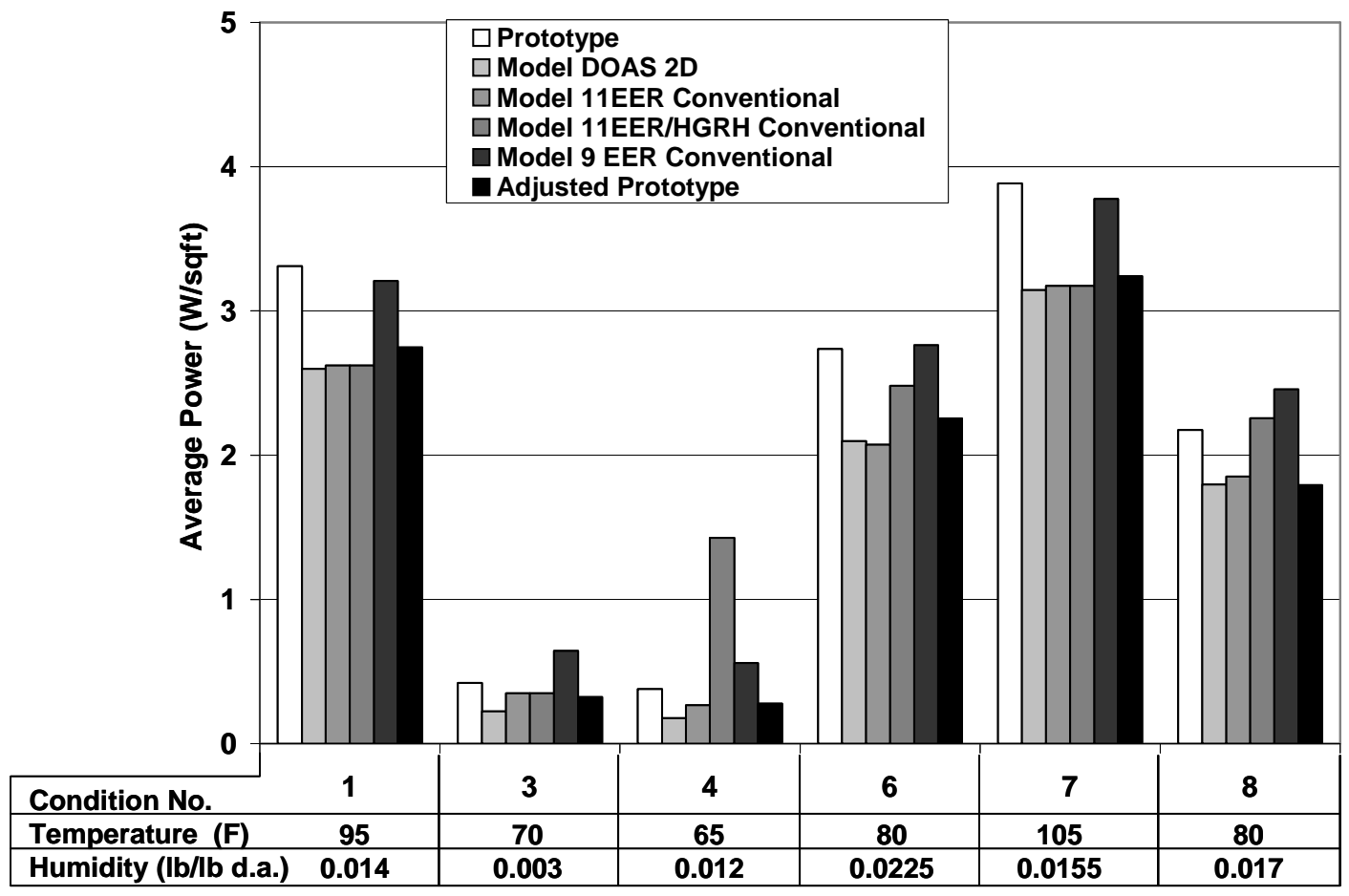

Note: $20 \mathrm{~W}$ VSD power eliminated from Prototype data for this comparison

Figure 26: IDOAS Prototype Energy Use Summary-Full Air Flow 
The comparison of the data shows that cooling season energy performance for the IDOAS unit is expected to be comparable to that of a conventional unit with roughly the same EER. The prototype as tested has an EER of roughly 9, and its off-design energy use is very close to that of the conventional 9EER unit. The energy use estimates for the adjusted prototype is very close to that of the 11EER conventional unit. The energy benefit of the IDOAS design becomes more clear when comparing energy use with that of a conventional unit with hot gas reheat, a design feature which is used to improve the ability of the conventional unit to provide dehumidification when the sensible loads are low. The comfort performance of the IDOAS and the conventional unit with hot gas reheat are comparable. However, energy use of the IDOAS is significantly less for ambient conditions in which the required latent capacity is high (i.e. ambient conditions with high humidity levels, particularly conditions 4, 6, and 8).

The performance benefit of VAV operation is illustrated in Table 16 below. The table compares capacities and energy input of the unit for three conditions with the return blower operating at full flow (as would occur for a unit without VAV operation) and with the return blower operating at half-speed. The data show the significant energy benefit of allowing variation in blower speed to reduce energy use. The half-air-flow performance also has significantly lower sensible heat ratio, which provides additional benefit for operation in humid climates. The reduced sensible heat ratio is due to the reduction in evaporator temperature associated with operating with lower air flow.

Table 16: Comparison of Full-Air-Flow and Half-Air-Flow Performance

\begin{tabular}{|c|c|c|c|c|c|c|c|c|c|c|c|}
\hline \multirow[b]{2}{*}{ 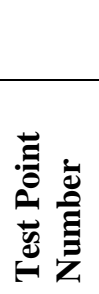 } & \multirow[b]{2}{*}{ 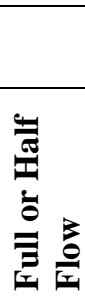 } & \multicolumn{2}{|c|}{ Outdoor Air } & \multicolumn{2}{|c|}{$\begin{array}{l}\text { Operating } \\
\text { Compressors }\end{array}$} & \multirow[b]{2}{*}{ 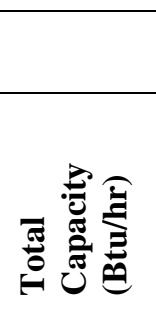 } & \multirow[b]{2}{*}{ 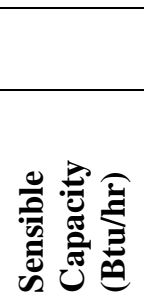 } & \multirow[b]{2}{*}{ 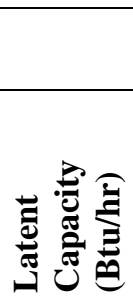 } & \multirow[b]{2}{*}{ 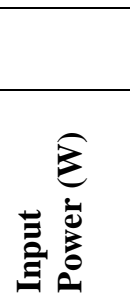 } & \multirow[b]{2}{*}{ 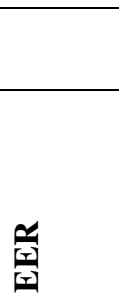 } & \multirow[b]{2}{*}{ 嶂 } \\
\hline & & 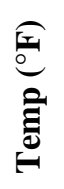 & 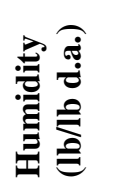 & to & 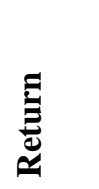 & & & & & & \\
\hline $3-2$ & Full & 70 & 0.0030 & 2 & Off & 15,000 & 15,000 & 0 & 2,650 & 5.66 & 1.00 \\
\hline $3-3 v$ & Half & 70 & 0.0030 & Off & 2 & 31,700 & 30,600 & 1,100 & 2,900 & 10.93 & 0.97 \\
\hline $8-3$ & Full & 80 & 0.0170 & 1,2 & 1 & 92,000 & 56,500 & 35,500 & 8,300 & 11.08 & 0.61 \\
\hline $8-4$ & & & & 1,2 & 2 & 93,400 & 57,700 & 35,700 & 8,350 & 11.19 & 0.62 \\
\hline $8-3 v$ & Half & 80 & 0.0170 & 1,2 & 1 & 84,500 & 45,400 & 39,100 & 6,950 & 12.16 & 0.54 \\
\hline $8-4 v$ & & & & 1,2 & 2 & 86,000 & 45,400 & 40,600 & 7,150 & 12.03 & 0.53 \\
\hline
\end{tabular}

When using the half-air-flow results in the average energy use calculation described in Table 15, the specific energy use for ambient condition 3 decreases from 0.42 to $0.29 \mathrm{~W} / \mathrm{sqft}$, while for ambient condition 8 the reduction is from 2.17 to $2.13 \mathrm{~W} / \mathrm{sqft}$. The decrease is low for ambient condition 8, because the run time for the operating configuration having only one return compressor and both outdoor compressors operating is relatively low (less than $40 \%$ for the full-air-flow case). These results show that energy use can be significantly reduced when allowing the blower speed to be reduced during part-load operation, but that the magnitude of the impact is strongly dependent on the duty cycle of return-air side part-load operation. 


\subsection{Testing with Energy Recovery Wheel}

Testing of the unit with the energy recovery wheel assembly connected was done for two ambient conditions with high outdoor air cooling loads (\#1: $95^{\circ} \mathrm{F}$ DB temperature / $0.014 \mathrm{lb} / \mathrm{lb}$ d.a. humidity ratio; and \#6: $80^{\circ} \mathrm{F} \mathrm{DB} / 0.022 \mathrm{lb} / \mathrm{lb}$ d.a.). The unit was operated with exhaust air flow rate equal to outdoor air flow rate. This is a best-case scenario for most buildings, since some amount of air leaving the building is often associated with toilet exhaust (which is not recirculated and generally is not used for energy recovery) and because positive pressurization of buildings is important especially in warm humid climates to prevent condensation of water vapor in the building's walls. For the ERW tests, outdoor air is cooled significantly with the ERW, thus making one stage of compressor cooling sufficient to cool the outdoor air. Only outdoor compressor circuit \#2 was used for the ERW tests. Two sets of ERW tests were done. For one of these, compressor circuit \#2 was operating with the same portions of the condenser and evaporator used for all of the other tests. This is the "separate" test series, designated "es" in the results. For the second set of tests, the condenser and evaporator circuits associated with Outdoor compressor \#1 were connected to Outdoor compressor \#2, using the valving system illustrated in Figure 13. This is the "combined" test series, designated "ec".

The test results are compared in Table 17 below with corresponding test data for operation without the energy recovery wheel. The corresponding tests are those with the

Table 17: Comparison of Standard and ERW Configuration Performance

\begin{tabular}{|c|c|c|c|c|c|c|c|c|c|c|}
\hline \multirow[b]{2}{*}{ 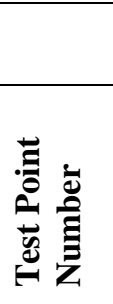 } & \multicolumn{2}{|c|}{$\begin{array}{l}\text { Condenser Air/ } \\
\text { Outdoor Air }^{1} \\
\end{array}$} & \multicolumn{2}{|c|}{$\begin{array}{l}\text { Operating } \\
\text { Compressors }\end{array}$} & \multirow[b]{2}{*}{ 预导 } & \multirow[b]{2}{*}{ 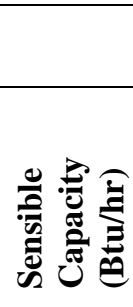 } & \multirow[b]{2}{*}{ 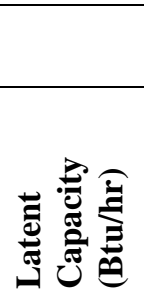 } & \multirow[b]{2}{*}{ 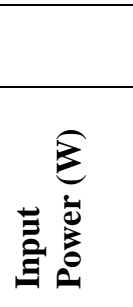 } & \multirow[b]{2}{*}{ 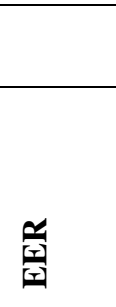 } & \multirow[b]{2}{*}{$\frac{\mathscr{r}}{\omega}$} \\
\hline & 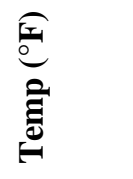 & 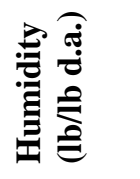 & 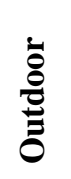 & 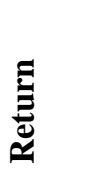 & & & & & & \\
\hline $1-2$ & $95 / 95$ & 0.0140 & 1,2 & 1,2 & 87,900 & 65,300 & 22,600 & 11,250 & 7.81 & 0.74 \\
\hline 1-2es & $95 / 97$ & 0.0140 & 2 & 1,2 & 101,600 & 72,600 & 28,900 & 9,520 & 10.67 & 0.71 \\
\hline $1-2$ ec & 95/98 & 0.0140 & 2 & 1,2 & 94,100 & 70,900 & 23,300 & 9,200 & 10.27 & 0.75 \\
\hline $1-4 \mathrm{es}$ & $95 / 100$ & 0.0170 & 2 & 2 & 85,900 & 57,500 & 28,500 & 6,870 & 12.51 & 0.67 \\
\hline $6-2$ & $80 / 80$ & 0.0225 & 1,2 & 1,2 & 93,300 & 50,000 & 43,300 & 9,300 & 10.03 & 0.54 \\
\hline 6-2es & $80 / 88$ & 0.022 & 2 & 1,2 & 137,300 & 73,000 & 64,300 & 8,270 & 16.61 & 0.53 \\
\hline 6-2ec & 80/88 & 0.022 & 2 & 1,2 & 117,100 & 66,500 & 50,500 & 8,020 & 14.60 & 0.57 \\
\hline
\end{tabular}

Notes:

1. For the ERW tests, outdoor air entering the ERW was higher than the target levels, due to preheating of the exhaust air by the ERW and the blower heat contribution of the exhaust blower. The two numbers shown for ambient temperature represent average condenser air inlet temperature and outdoor air entering the energy recovery wheel portion of the unit. 
same target ambient conditions, with the same number of return compressors operating, but with one more outdoor compressor operating. The power input for the ERW tests includes power for the exhaust blower which was measured during a separate test for which the outdoor air conditioning loop was not connected. Note that there was no corresponding standard-configuration test for 1-4es. With the ERW, the unit consistently provides more capacity, even though fewer compressors are operating. It must be noted that outdoor dry bulb temperature was somewhat higher than in the standardconfiguration tests, due to prewarming by the ERW and the heat addition of the exhaust blower. For the ERW tests, EER is also much higher, since capacity is higher and input power is lower.

The differences between "separate" and "combined" operation of the outdoor circuits are unexpected. We anticipated that increasing heat exchanger surface area would increase capacity. However, in all cases, the "combined” tests resulted in reduced capacity. For all of these tests, condensing temperature decreased, evaporator temperature increased, and power input decreased. The reduction in capacity is primarily due to the reduction of subcooling and possibly passing of uncondensed refrigerant out of the condenser (refrigerant charge was not re-optimized after combining the two circuits). Note that the "combined" series of tests has significantly higher SHR, consistent with the raised evaporating temperature.

Contribution to overall unit capacity of the ERW was estimated based on single-point measurements of the ERW exit conditions at the center of its outdoor air segment. Due to the gradients in conditions typically present in the exit of an ERW, the measurements are just an approximation. These measurements and implications regarding ERW effectiveness and contribution to overall unit capacity are summarized in Table 18 below.

Table 18: Examination of Energy Recovery Wheel Capacity Contribution

\begin{tabular}{|c|c|c|c|c|c|c|c|c|c|c|c|c|}
\hline \multirow[b]{2}{*}{ 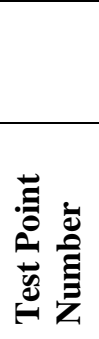 } & \multicolumn{2}{|c|}{$\begin{array}{l}\text { Outdoor Air } \\
\text { Entering } \\
\text { ERW } \\
\end{array}$} & \multicolumn{2}{|c|}{$\begin{array}{l}\text { Air } \\
\text { Leaving } \\
\text { ERW }^{1}\end{array}$} & \multicolumn{2}{|c|}{ Return Air } & \multicolumn{3}{|c|}{ Measured Effectiveness } & \multicolumn{3}{|c|}{$\begin{array}{l}\text { Calculated ERW Load } \\
\text { (Btu/hr) }\end{array}$} \\
\hline & 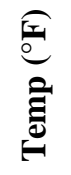 & 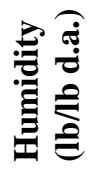 & 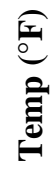 & 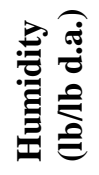 & 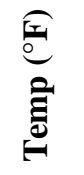 & $\begin{array}{l}\text { 象兽 } \\
\text { 恶 }\end{array}$ & م. & 䒿 & 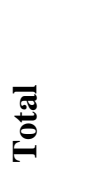 & 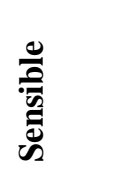 & 氖 & 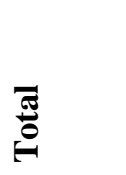 \\
\hline $1-2 \mathrm{ec}$ & 98 & 0.014 & 81 & 0.009 & 76 & 0.009 & $77 \%$ & $100 \%$ & $89 \%$ & 14,000 & 19,200 & 33,300 \\
\hline $1-4 \mathrm{es}$ & 100 & 0.017 & 80 & 0.009 & 75 & 0.009 & $80 \%$ & $100 \%$ & $92 \%$ & 16,200 & 30,200 & 46,400 \\
\hline 6-2es & 88 & 0.022 & 77 & 0.011 & 74 & 0.009 & $79 \%$ & $85 \%$ & $84 \%$ & 9,300 & 42,600 & 51,800 \\
\hline 6-2ec & 88 & 0.022 & 79 & 0.012 & 74 & 0.009 & $64 \%$ & $77 \%$ & $75 \%$ & 7,500 & 38,500 & 46,000 \\
\hline
\end{tabular}

Notes:

1. Air leaving conditions were measured directly after ERW at roughly the midpoint of the outdoor air half of the wheel. Stratification of air leaving the wheel cannot be entirely avoided for this measurement.

2. ERW leaving conditions were not measured for test 1-2es. 
There is some variation in calculated effectiveness, due most likely to the difficulty in measuring true average conditions, but the performance of the ERW is more or less consistent with expectations. The calculated ERW contributions to unit capacity are large, in all tested cases exceeding the capacity of the displaced compressor. SHR of the ERW capacity contribution reflects the conditioning requirement for the incoming air. For the warm humid condition \#6, SHR is as low as $16 \%$.

The transfer of latent load from the cooling coils to the energy recovery wheel is illustrated in Figure 27 below. The chart shows the unit's latent capacity as compared with the condensate collected during a portion of operational testing. The line in the chart corresponds to $1,061 \mathrm{Btu} / \mathrm{lb}$ of water. The chart clearly shows that for tests of the unit while using the ERW most of the latent capacity cannot be accounted for in the measured condensate flow. This shows that the moisture is being removed by the ERW rather than the evaporators.

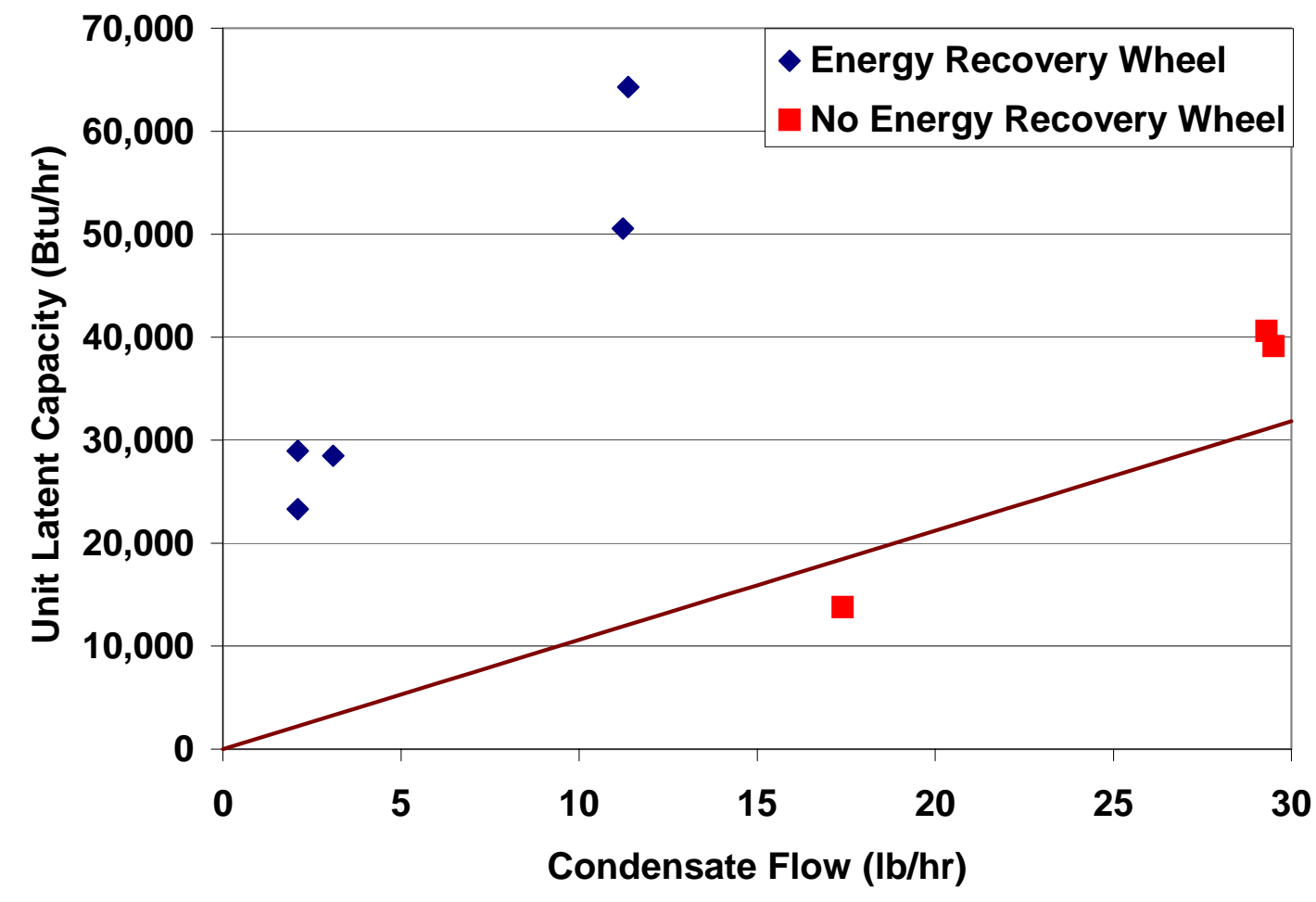

Figure 27: Latent Capacity Comparison with Condensate Flow 


\section{Conclusions and Recommendations}

A design for a 10-ton unitary rooftop air-conditioner with an integrated dedicated outdoor air system (IDOAS) was developed and a prototype of the unit was built and tested. The performance level of the prototype did not match design expectations at ARI rating conditions due to numerous issues associated with the system components and our ambitious approach to packaging the unit in a size which did not allow sufficient space for the blowers. However, both analysis and test data show that the IDOAS has distinct performance advantages as compared with conventional equipment which allow it to meet the conditioning needs of typical office spaces over a wide range of ambient conditions without the need for hot gas reheat to boost latent performance when ambient conditions are moderate but humid.

Annual energy savings on the order of $10 \%$ were predicted by analysis for an office building scenario when targeting interior conditions of $75^{\circ} \mathrm{F}$ and $50 \%$ relative humidity. This result is based on comparison of a conventional unit and an IDOAS unit with comparable EER. For this analysis, the predicted space humidity would exceed $50 \%$ for the conventional 11 EER unit for more than 1,000 hours for a Fort Worth office scenario. These are hours for which the IDOAS unit is predicted to maintain the $50 \%$ relative humidity in the space by shifting load to the compressors serving the outdoor air. During humid conditions, the IDOAS adjusts to provide enhanced latent capacity. However, during dry conditions, the IDOAS shifts load to the return air compressors, thus reducing the tendency for overdrying, which unnecessarily adds to the energy use of the conventional unit.

Testing of the IDOAS prototype for off-design conditions showed roughly that an IDOAS unit will incur energy use comparable to that of a conventional unit with equal EER. Hence, the $10 \%$ additional savings which the analysis predicted was not borne out in testing. In fairness, due to the superior latent performance of the IDOAS unit, a more fitting energy comparison would be with a unit which uses hot gas reheat to enhance latent performance. This technique, which is gaining acceptance in the industry as a simple first-cost-effective approach for improving latent performance, results in significantly more energy use. Our analysis shows that the hot gas reheat approach will use $15 \%$ more energy than a conventional unit without hot gas reheat in a Forth Worth Office scenario when attempting to maintain $50 \%$ space relative humidity. Hence, the IDOAS approach could be credited with achieving $15 \%$ energy savings.

Further development of the IDOAS would focus on optimization of the package in order to accommodate sufficient space for the blowers to operate efficiently. Other issues which have been considered but not fully resolved during the course of the development include the following.

- Control of outdoor air flow when the return blower is not operating in order to assure constant outdoor air flow. Some options were discussed in Section 3. Selection of a specific approach will depend on application-specific requirements. A flexible approach in which the best of these options could be selected by the equipment buyer may be the most appropriate plan. 
- A control algorithm was developed for selecting unit operating configurations for analysis. However, control algorithms for maintaining space conditions must be developed and tested for actual unit operation.

- Further design work would be required as an IDOAS unit moves from the concept and prototype phase to production. Many specific design decisions would be made which will be impacted by plans for the range of capacities offered in such a product line. 


\section{References}

1. Mumma, Stanley A., “Designing Dedicated Outdoor Air Systems”, ASHRAE Journal, May 2001, p. 28.

2. Morris, Wayne, “The ABCs of DOAS”, ASHRAE Journal, May 2003, p.24.

3. Carrier Form 48H,T-2PD, Product Data for 48TF004-014, 48TJ016-028, 48HJ004017 Single-Package Rooftop Units, Gas Heating/Electric Cooling, 3 to 25 Nominal Tons, 2002

4. Huang, J., "481 Prototypical Commercial Buildings for Twenty Urban Market Areas”, Lawrence Berkeley Laboratory, June 1990.

5. Huang, J., and E.Franconi, "Commercial Heating and Cooling Loads Component Analysis”, Lawrence Berkeley National Laboratory, November 1999.

6. Westphalen, D., S.Koszalinski, "Energy Consumption Characteristics of Commercial Building HVAC Systems Volume I: Chillers, Refrigerant Compressors, and Heating Systems”, prepared by Arthur D. Little, Inc. for U.S.DOE, April 2001.

7. "Energy Efficient Building Equipment and Envelope Technologies, Round III", DOE Solicitation DE-PS26-01NT41092, December 2000.

8. Shirey, D.B. and H.I. Henderson, "Dehumidification at Part Load", ASHRAE Journal 46 (4):42-48, April 2004.

9. Brennan, T. and H.Burge, “Assessing Mold in Buildings”, ASHRAE Journal 47 (1):S158-S164, January 2005.

10. Ogg, B., "Managing House Dust Mites”, University of Nebraska Lincoln Extension website, http://lancaster.unl.edu/pest/resources/DustMites311.shtml.

11. 10 CFR 431.97 (b) 


\section{Appendix 1: Control Description}

The tables attached provide a summary of the controls for the IDOAS prototype with intended interfaces for both laboratory and field operation.

Table 19: Controlled Components Description

\begin{tabular}{|c|c|c|c|c|c|c|c|}
\hline \multirow[t]{2}{*}{ Component } & \multirow{2}{*}{$\begin{array}{l}\text { Num- } \\
\text { ber }\end{array}$} & \multicolumn{4}{|c|}{ Motor Description } & \multirow{2}{*}{$\begin{array}{l}\text { Max } \\
\text { Amps }\end{array}$} & \multirow[t]{2}{*}{ Comments } \\
\hline & & Volts & Phases & SS/VS & hp & & \\
\hline Condenser Fan & 2 & $208 / 230$ & 1 & SS & $1 / 4$ & & \\
\hline Outdoor Blower & 1 & 208 & 3 & VS & 1.5 & & \\
\hline Return Blower & 1 & 208 & 3 & VS & 3 & & \\
\hline Compressors & 4 & 208 & 3 & SS & -3.5 & & \\
\hline $\begin{array}{l}\text { OA Throttling } \\
\text { Damper Motor }\end{array}$ & 1 & 24 & $\begin{array}{l}\text { DC or } \\
\text { AC }\end{array}$ & $\begin{array}{l}\text { Open/ } \\
\text { Close }\end{array}$ & & & Open/Closed \\
\hline ERW & 1 & 120 & 1 & SS & & & \\
\hline Exhaust Blower & 1 & 208 & 3 & SS & 1 & & \\
\hline
\end{tabular}

Table 20: Controls for Laboratory Operation

\begin{tabular}{|c|c|c|c|}
\hline Description & $\frac{\grave{d}}{\grave{c}}$ & Type & Comments \\
\hline HP Cutout & 4 & Pressure Switch & In Compressor Starter Circuits \\
\hline LP Cutout & 4 & Pressure Switch & In Compressor Starter Circuits \\
\hline $\begin{array}{l}\text { Outdoor Blower } \\
\text { Speed Pot }\end{array}$ & 1 & PLC Input, Pot & \\
\hline $\begin{array}{l}\text { Return Blower Speed } \\
\text { Pot }\end{array}$ & 1 & PLC Input, Pot & \\
\hline Component ON/OFF & 10 & PLC Input, Switch & $\begin{array}{l}\text { Condenser Fans, Outdoor Blower, Return } \\
\text { Blower, Compressors, ERW, Exhaust } \\
\text { Blower } \\
\text { PLC logic to prevent energizing } \\
\text { compressor contactors if no condenser } \\
\text { contactor is energized. }\end{array}$ \\
\hline $\begin{array}{l}\text { OA Throttling Damper } \\
\text { Switch }\end{array}$ & 1 & PLC Input, Switch & \\
\hline Component ON/OFF & 10 & PLC Output & $\begin{array}{l}\text { Signals to Motor Starters or Contactors: } \\
\text { Condenser Fans, Outdoor Blower, Return } \\
\text { Blower, Compressors, ERW, Exhaust } \\
\text { Blower }\end{array}$ \\
\hline $\begin{array}{l}\text { Outdoor Blower } \\
\text { Speed }\end{array}$ & 1 & PLC Output & Signal to VFD \\
\hline Return Blower Speed & 1 & PLC Output & Signal to VFD \\
\hline $\begin{array}{l}\text { OA Throttling Damper } \\
\text { Actuation }\end{array}$ & 1 & PLC Output & Signal to Damper Motor \\
\hline
\end{tabular}


Table 21: Anticipated Field Installation Controls

\begin{tabular}{|c|c|c|c|}
\hline Description & $\begin{array}{l}\bar{\Xi} \\
\bar{\Xi} \\
\bar{\Xi}\end{array}$ & Type & Comments \\
\hline HP Cutout & 4 & Pressure Switch & In Compressor Starter Circuits \\
\hline LP Cutout & 4 & Pressure Switch & In Compressor Starter Circuits \\
\hline Vent-Cool-Off Switch & 1 & PLC Input, Selector Switch & \\
\hline Space Temperature & 1 & PLC Input, Temperature & \\
\hline Space Humidity & 1 & PLC Input, Humidity & \\
\hline Outdoor Temperature & 1 & PLC Input, Temperature & \\
\hline Outdoor Humidity & 1 & PLC Input, Humidity & \\
\hline Freezestat & 4 & PLC Input, Thermostat & \\
\hline $\begin{array}{l}\text { OA Discharge } \\
\text { Temperature }\end{array}$ & 1 & PLC Input, Temperature & \\
\hline $\begin{array}{l}\text { RA Discharge } \\
\text { Temperature }\end{array}$ & 1 & PLC Input, Temperature & \\
\hline ERW OA Side DP & 1 & PLC Input, Pressure & Possible but not high probability \\
\hline Component ON/OFF & 10 & PLC Output & $\begin{array}{l}\text { Signals to Motor Starters or } \\
\text { Contactors: Condenser Fans, } \\
\text { Outdoor Blower, Return Blower, } \\
\text { Compressors, ERW, Exhaust } \\
\text { Blower }\end{array}$ \\
\hline $\begin{array}{l}\text { Outdoor Blower } \\
\text { Speed }\end{array}$ & 1 & PLC Output & Signal to VFD \\
\hline Return Blower Speed & 1 & PLC Output & Signal to VFD \\
\hline $\begin{array}{l}\text { OA Throttling Damper } \\
\text { Actuation }\end{array}$ & 1 & PLC Output & Signal to Damper Motor \\
\hline
\end{tabular}




\section{Appendix 2: Detailed Prototype Test Data}

This appendix includes the performance test data collected during the course of the project. A summary of capacity and power input data is presented in Table 22 below.

Table 22: IDOAS Prototype Performance Test Data Summary

\begin{tabular}{|c|c|c|c|c|c|c|c|c|c|c|}
\hline \multirow{2}{*}{ 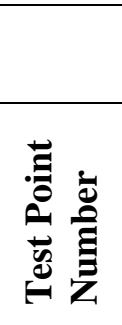 } & \multirow[b]{2}{*}{ 总 } & \multicolumn{2}{|c|}{ Outdoor Air } & \multicolumn{2}{|c|}{$\begin{array}{l}\text { Operating } \\
\text { Compressors } \\
\end{array}$} & \multirow[b]{2}{*}{ 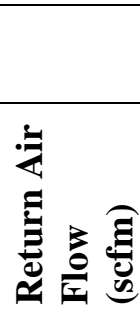 } & \multirow[b]{2}{*}{ 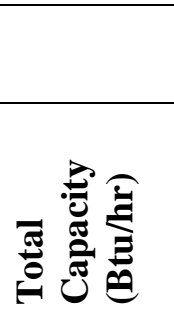 } & \multirow[b]{2}{*}{ 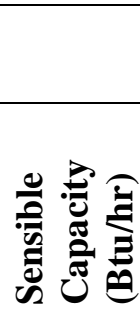 } & \multirow[b]{2}{*}{ 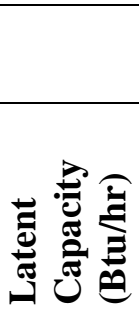 } & \multirow[b]{2}{*}{ 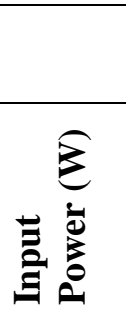 } \\
\hline & & 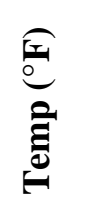 & 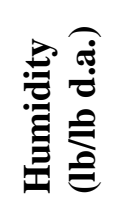 & $\frac{\grave{o}}{\grave{\Xi}}$ & 氞 & & & & & \\
\hline \multirow[t]{2}{*}{$\mathrm{ARI}^{1}$} & 1 & 95 & 0.0150 & 1,2 & 1,2 & 2,740 & 107,000 & 75,800 & 31,200 & 12,250 \\
\hline & 2 & & 0.0150 & 1,2 & 1,2 & 2,380 & 105,300 & 69,300 & 36,000 & 11,650 \\
\hline \multirow[t]{3}{*}{1} & 1 & 95 & 0.0140 & 2 & 1,2 & \multirow{19}{*}{2,800} & 64,900 & 57,800 & 7,100 & 8,550 \\
\hline & 2 & & & 1,2 & 1,2 & & 87,900 & 65,300 & 22,600 & 11,250 \\
\hline & 3 & & & 1 & 1,2 & & 65,900 & 57,600 & 8,300 & 8,550 \\
\hline \multirow[t]{2}{*}{3} & 1 & 70 & 0.0030 & 1 & Off & & 14,700 & 14,700 & 0 & 2,650 \\
\hline & 2 & & & 2 & Off & & 15,000 & 15,000 & 0 & 2,650 \\
\hline \multirow[t]{3}{*}{4} & 1 & 65 & 0.0120 & 1 & Off & & 23,800 & 8,300 & 15,500 & 2,600 \\
\hline & 2 & & & 2 & Off & & 23,600 & 7,700 & 15,900 & 2,600 \\
\hline & 3 & & & 1,2 & Off & & 43,200 & 16,300 & 26,900 & 4,000 \\
\hline \multirow[t]{4}{*}{6} & 1 & 80 & 0.0225 & 1,2 & Off & & 54,500 & 13,500 & 41,000 & 4,800 \\
\hline & 2 & & & 1,2 & 1,2 & & 93,300 & 50,000 & 43,300 & 9,300 \\
\hline & 3 & & & 1,2 & 1 & & 79,400 & 44,600 & 34,800 & 7,250 \\
\hline & 4 & & & 1,2 & 2 & & 81,700 & 46,200 & 35,500 & 7,550 \\
\hline 7 & 1 & 105 & 0.0155 & 1,2 & 1,2 & & 91,400 & 79,000 & 12,400 & 13,200 \\
\hline \multirow[t]{6}{*}{8} & 1 & 80 & 0.0170 & 1,2 & 1,2 & & 99,500 & 69,600 & 29,900 & 10,220 \\
\hline & 2 & & & 1,2 & Off & & 47,300 & 17,200 & 30,100 & 4,750 \\
\hline & 3 & & & 1,2 & 1 & & 92,000 & 56,500 & 35,500 & 8,300 \\
\hline & 4 & & & 1,2 & 2 & & 93,400 & 57,700 & 35,700 & 8,350 \\
\hline & 5 & & & 1 & 1,2 & & 95,200 & 68,100 & 27,100 & 8,400 \\
\hline & 6 & & & 2 & 1,2 & & 92,800 & 66,300 & 26,500 & 8,300 \\
\hline 3 & 2-vav & 70 & 0.0030 & Off & 2 & 1,320 & 31,700 & 30,600 & 1,100 & 2,900 \\
\hline \multirow[t]{2}{*}{8} & 3-vav & 80 & 0.0170 & 1,2 & 1 & 1,340 & 84,500 & 45,400 & 39,100 & 6,950 \\
\hline & 4-vav & & & 1,2 & 2 & 1,340 & 86,000 & 45,400 & 40,600 & 7,150 \\
\hline \multirow[t]{3}{*}{1} & $2-e^{3}$ & $95^{2}$ & 0.0140 & 2 & 1,2 & 2,660 & 101,600 & 72,600 & 28,900 & 9,520 \\
\hline & 2-ес & & & 2 & 1,2 & 2,614 & 94,100 & 70,900 & 23,300 & 9,200 \\
\hline & 4-es & & & 2 & 2 & 1,614 & 85,900 & 57,500 & 28,500 & 6,870 \\
\hline \multirow[t]{2}{*}{6} & 2-es & $80^{2}$ & 0.022 & 2 & 1,2 & 2,608 & 137,300 & 73,000 & 64,300 & 8,270 \\
\hline & 2-ес & & 0.022 & 2 & 1,2 & 2,607 & 117,100 & 66,500 & 50,500 & 8,020 \\
\hline
\end{tabular}


Table Notes:

1. ARI Capacity Test. Outdoor air flow rates for these tests were $880 \mathrm{cfm}$ for Test 1 and $870 \mathrm{cfm}$ for Test 2 . Outdoor air flow rates for the Off-design tests 1 through 8 were $800 \mathrm{cfm}$.

2. Outdoor air temperature entering the ERW rose higher than the desired conditions, due to the preheating of the energy recovery wheel and the blower heat addition of the exhaust blower. Actual temperatures entering the ERW were as follows for these tests.

- 1-2es: $97^{\circ} \mathrm{F}$

- 1-2ec: $98^{\circ} \mathrm{F}$

- 1-4es: $100^{\circ} \mathrm{F}$

- 6-2es: $88^{\circ} \mathrm{F}$

- 6-2ec: $88^{\circ} \mathrm{F}$

3. Test point numbers es are for prototype configurations in which outdoor air compressor 2 is serving its own refrigerant circuit. Test point numbers ec are for configurations in which circuits 1 and 2 have been combined and are served by compressor 2, using valves illustrated in Figure 13. 